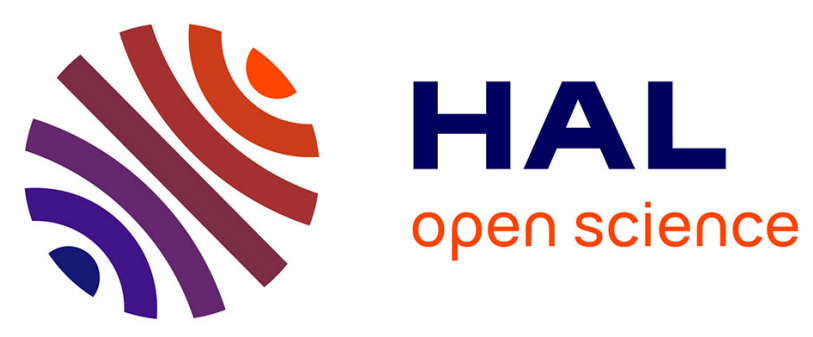

\title{
Genome editing reveals reproductive and developmental dependencies on specific types of 2 vitellogenin in zebrafish (Danio rerio)
}

Ozlem Yilmaz, Amélie Patinote, Thuy Thao Vi Nguyen, Emmanuelle Com, Charles Pineau, Julien Bobe

\section{To cite this version:}

Ozlem Yilmaz, Amélie Patinote, Thuy Thao Vi Nguyen, Emmanuelle Com, Charles Pineau, et al.. Genome editing reveals reproductive and developmental dependencies on specific types of 2 vitellogenin in zebrafish (Danio rerio). 2018. hal-02791030

\section{HAL Id: hal-02791030 \\ https://hal.inrae.fr/hal-02791030}

Preprint submitted on 5 Jun 2020

HAL is a multi-disciplinary open access archive for the deposit and dissemination of scientific research documents, whether they are published or not. The documents may come from teaching and research institutions in France or abroad, or from public or private research centers.
L'archive ouverte pluridisciplinaire HAL, est destinée au dépôt et à la diffusion de documents scientifiques de niveau recherche, publiés ou non, émanant des établissements d'enseignement et de recherche français ou étrangers, des laboratoires publics ou privés. 
1 Title: Genome editing reveals reproductive and developmental dependencies on specific types of

2 vitellogenin in zebrafish (Danio rerio)

4 Ozlem Yilmaz ${ }^{1,3 *}$, Amelie Patinote ${ }^{1}$, Thaovi Nguyen ${ }^{1},{\text { Emmanuelle } \text { Com }^{2} \text {, Charles Pineau }}^{2}$, Julien Bobe ${ }^{1}$.

$6{ }^{1}$ INRA, UR1037, Laboratory of Fish Physiology and Genomics, Campus de Beaulieu, 35042 Rennes

7 Cedex, France.

$8 \quad{ }^{2}$ Protim, Inserm U1085, Irset, Campus de Beaulieu, 35042 Rennes Cedex, France.

$9 \quad{ }^{3}$ Present address: Institute of Marine Research, Austevoll Research Station, 5392, Storebø, Norway

10 ozlem.yilmaz@hi.no.

\section{ABSTRACT}

13 Oviparous vertebrates produce multiple forms of vitellogenin (Vtg), the major source of yolk

14 nutrients, but little is known about their individual contributions to reproduction and development. This

15 study employed a CRISPR/Cas9 genome editing to assess essentiality and functionality of zebrafish

16 (Danio rerio) type-I and -III Vtgs. The multiple CRISPR approach employed to knock out (KO) all genes

17 encoding type-I vtgs (vtg1, 4, 5, 6, and 7) simultaneously (vtg1-KO), and the type-III vtg (vtg3)

18 individually (vtg3-KO). Results of PCR genotyping and sequencing, qPCR, LC-MS/MS and Western

19 blotting showed that only vtg6 and vtg7 escaped Cas9 editing. In fish whose remaining type-I vtgs were

20 incapacitated ( $v \operatorname{tg} 1-\mathrm{KO}$ ), and in $v \operatorname{tg} 3-\mathrm{KO}$ fish, significant increases in $\mathrm{Vtg} 7$ transcript and protein levels

21 occurred in liver and eggs, a heretofore-unknown mechanism of genetic compensation to regulate Vtg

22 homeostasis. Fecundity was more than doubled in $v \operatorname{tg} 1-\mathrm{KO}$ females, and fertility was $\sim$ halved in $v \operatorname{tg} 3-\mathrm{KO}$

23 females. Substantial mortality was evident in $v \operatorname{tg} 3-\mathrm{KO}$ eggs/embryos after only $8 \mathrm{~h}$ of incubation and in

$24 v t g 1-\mathrm{KO}$ embryos after $5 \mathrm{~d}$. Hatching rate and timing were markedly impaired in $v \operatorname{tg}$ mutant embryos and

25 pericardial and yolk sac/abdominal edema and spinal lordosis were evident in the larvae, with feeding and

26 motor activities also being absent in vtgl-KO larvae. By late larval stages, vtg mutations were either 
27 completely lethal $(v \operatorname{tg} 1-\mathrm{KO})$ or nearly so $(v \operatorname{tg} 3-\mathrm{KO})$. These novel findings offer the first experimental

28 evidence that different types of vertebrate Vtg are essential and have disparate requisite functions at

29 different times during both reproduction and development.

31 Keywords; CRISPR/Cas9, knock out, vitellogenins, zebrafish

\section{INTRODUCTION}

In oviparous animals, maternally supplied vitellogenins (Vtgs) are the major source of yolk

35 nutrients supporting early development. Vertebrate Vtgs are specialized members of a superfamily of

36 large lipid transfer proteins that are preferentially produced by the liver and transported via the

37 bloodstream to the ovary (Babin et al., 2007). The Vtgs are taken up into growing oocytes via receptor-

38 mediated endocytosis (Opresko and Wiley, 1987), where they are processed by the lysosomal

39 endopeptidase, cathepsin D, into product yolk proteins that are stored in the ooplasm (Carnevali et al.,

40 1999a,b, 2006). Jawed vertebrates produce three major forms of Vtg arising from a vtg gene cluster that

41 was present in the ancestor of tetrapods and ray-finned fish (Babin, 2008; Finn et al., 2009). During

42 vertebrate evolution these ancestral $v t g$ genes were subject to whole genome duplications, loss of paralogs

43 and lineage-specific tandem duplications, giving rise to substantial variation in the repertoire and number

44 of $v t g$ genes present in an individual species, especially among teleost fish (Andersen et al., 2017). The

45 linear yolk protein domain structure of complete teleost $\mathrm{Vtgs}$ is: $\mathrm{NH}_{2}$-lipovitellin heavy chain (LvH)-

46 phosvitin $(\mathrm{Pv})$-lipovitellin light chain $(\mathrm{LvL})$-beta component $(\beta$ 'c)-C-terminal component $(\mathrm{Ct})-\mathrm{COOH}$

47 (Patiño and Sullivan, 2002; Hiramatsu et al., 2005). Most teleosts possess from two to several forms of A-

48 type Vtg (VtgA), which may be complete or incomplete, as well an incomplete C-type Vtg (VtgC)

49 lacking both $\mathrm{Pv}$ and the two small $\mathrm{C}$-terminal yolk protein domains $(\beta$ 'c and $\mathrm{Ct})$. For example, the

50 complex zebrafish (Danio rerio) Vtg repertoire includes five type-I Vtgs (Vtg 1, 4, 5, 6 and 7) that are

51 incomplete, lacking $\beta^{\prime}-\mathrm{c}$ and $\mathrm{Ct}$ domains (=ostariophysan VtgAo1), two type-II Vtgs (Vtg2 and Vtg8) that

52 are complete (=VtgAo2), and one type-III Vtg (Vtg3), which is a typical VtgC (Yilmaz et al., 2018). 
54 maturation and in embryonic and larval development has been target of attention for decades (Hiramatsu

55 et al., 2005; Reading and Sullivan, 2011; Sullivan and Yilmaz, 2018). The most diverse group of fishes,

56 the spiny-rayed teleosts (Acanthomorpha) generally possess two paralogous complete forms of VtgA

57 (VtgAa, and $\mathrm{Vtg} \operatorname{tg}$ ) in addition to $\mathrm{VtgC}$, and these are orthologs of the zebrafish type-I, type-II and type-

58 III Vtgs, respectively (Finn et al., 2009). In some marine species spawning pelagic eggs, the VtgAa has

59 become neofunctionalized so that its product yolk proteins are highly susceptible to proteolytic

60 degradation by cathepsins during oocyte maturation, yielding a pool of free amino acids (FAA) that

61 osmotically assist oocyte hydration and acquisition of proper egg buoyancy (Matsubara et al., 1999; Finn

62 and Kristoffersen, 2007) and that also serve as critical nutrients during early embryogenesis (Thorsen and

63 Fyhn, 1996; Finn and Fyhn, 2010). The major yolk protein derived from the corresponding VtgAb

64 (LvHAb) is less susceptible to maturational proteolysis. Based on its limited degradation during oocyte

65 growth and maturation, and its utilization late in larval life in some species, it has been proposed that the

$66 \mathrm{VtgC}$ may be specialized to deliver large lipoprotein nutrients to late stage larvae without affecting the

67 osmotically active FAA pool (Reading et al., 2009; Reading and Sullivan, 2011). Aside from these few

68 examples, very little is known about specific contributions of the different types of Vtg to developmental

69 processes in acanthomorphs, virtually nothing is known about specialized functions of individual types of

$70 \mathrm{Vtg}$ in other vertebrates, and no individual form of Vtg has been proven to be required for the

71 developmental competence of eggs or offspring.

72 The zebrafish has become an established biomedical model for research on reproduction and

73 developmental biology because they are small, easily bred in the laboratory with short generation time,

74 and lay clutches of numerous large eggs every few days, with external fertilization of the transparent eggs

75 in which embryonic development is easily observed (Ribas and Piferrer, 2013). A reference genome

76 sequence is available, providing the needed databases and bioinformatics tools to conduct genomic and

77 proteomic research on Vtgs in this species. Details on the genomic and protein domain structure of each

78 individual zebrafish Vtg and on their transcript expression and protein abundance profiles were recently 
made available by Yilmaz et al. (2018). Coupled with these advantages, the presence of multiple genes encoding the three classical major types of Vtg in zebrafish offers a unique opportunity to investigate

81 their essentiality and functionality via application of CRISPR/Cas9 (clustered regularly interspaced short

82 palindromic repeats (CRISPR)/CRISPR-associated protein 9) technology (Doudna and Charpentier,

83 2014), a powerful gene-editing tool that provides a reliable process for making precise, targeted changes

84 to the genome of living cells.

85 The extensive multiplicity of genes encoding type-I Vtgs, the major contributors to yolk proteins

86 in zebrafish eggs, is a matter of interest considering their lack of $\beta$ ' $c$ - and $\mathrm{Ct}$ - domains, which contain 14

87 highly conserved cysteine residues that are known to be involved in disulfide linkages required for

88 complex folding of the Vtg polypeptide and possibly for the dimerization of native Vtg thought to be

89 required for binding to its oocyte receptor (Reading et al., 2009; Reading and Sullivan 2011).

90 Additionally, the type-III Vtg ( VtgC), lacking all but Lv domains and usually being the least abundant

91 form of Vtg, but one universally present in teleosts, begs investigation regarding its contributions to early

92 development. Therefore, the main objectives of this study were to discover whether type-I Vtgs and type-

93 III Vtg (VtgC) are required for zebrafish reproduction, and to identify specific developmental periods and

94 processes to which they significantly contribute, by investigating the effects of knock out (KO) of their

95 respective genes using the CRISPR/Cas9 gene-editing tool.

\section{2. RESULTS}

Large deletion mutations of $1821 \mathrm{bp}$ and $1182 \mathrm{bp}$ of gDNA were introduced in zebrafish type-I

99 vtgs (vtg1-KO) and in vtg3 (vtg3-KO), respectively, via CRISPR/Cas9 genome editing. The introduced

100 deletions involved 703 bp and 714 bp of the respective transcripts, encoding 234 aa and 239 aa of their

101 respective polypeptide sequences, and they resulted in double strand breaks in the ORF in both cases (Fig

102 1, S1 Fig). For both $v \operatorname{tg} 1-\mathrm{KO}$ and $v \operatorname{tg} 3-\mathrm{KO}$, the introduced mutation altered the structure of the deduced

$103 \mathrm{LvH}$ chain of the Vtg polypeptide and, in the case of $v \operatorname{tg} 3-\mathrm{KO}$, it extended into the Vtg receptor-binding

104 domain (Fig 2, S1 Fig). Introduced mutations were detected by genotyping via PCR screening of gDNA 
105 at each generation using combinations of primers flanking each altered target site (Fig 1). F0 generation

106 individuals exhibiting a heterozygous mutant double banding pattern were retained as founders for 107 production of stable mutant lines (Fig 3).

108 Microinjection efficiency was acceptable and high, resulting in $20 \%$ and $80 \%$ mutation positive 109 embryos at $24 \mathrm{~h}$ screening, for $v \operatorname{tg} 1-\mathrm{KO}$ and $v \operatorname{tg} 3-\mathrm{KO}$, respectively. This efficiency was confirmed by

110 finclip genotyping when these embryos reached adulthood. However, mutation transmission to F1

111 offspring was as low as $0.010 \%$ for $v \operatorname{tg} 1-\mathrm{KO}$ and $0.025 \%$ for $v \operatorname{tg} 3-\mathrm{KO}$, and only 2 heterozygous (Ht:

$112 v \operatorname{tg} 1-/+$ and $v \operatorname{tg} 3-/+)$ adult males were available to continue reproductive crosses with non-related wild

113 type (Wt: $v \operatorname{tg} 1+/+$ and $v \operatorname{tg} 3+/+$ ) females for production of $\mathrm{F} 2$ generations. The rate of mutation

114 transmission to the F2 generation produced from F1 Ht males and Wt females was 55\% and 70\% for

$115 v t g 1-\mathrm{KO}$ and $v \operatorname{tg} 3-\mathrm{KO}$, respectively. Reproductive crosses of $\mathrm{Ht}$ males and $\mathrm{Ht}$ females revealed a

116 Mendelian inheritance pattern with $25 \%$ wild type (wt: sibling wild type; $v \operatorname{tg} 1+/+$ and $v \operatorname{tg} 3+/+$ ), $52 \%$

117 heterozygous and 22\% homozygous (Hm: vtg1-/- and vtg3-/-) individuals at the F3 generation. Hm F3

118 females and males were crossed to produce the F4 generation yielding $100 \%$ homozygous offspring

119 carrying only the mutated allele (Fig 3). As these Hm individuals are generally inviable (see below),

120 production of subsequent generations of mutants requires crossbreeding of heterozygotes.

121 For both $v \operatorname{tg} \mathrm{KO}$ lines, the relative level of expression of each individual $v$ tg transcript in livers of

$122 \mathrm{Hm}, \mathrm{Ht}$, and wt F3 generation females were compared to those obtained for Wt female liver. KO of type-I

$123 v \operatorname{tgs}$ resulted in the absence of $v \operatorname{tg} 1$, vtg4, and $v \operatorname{tg} 5$ transcripts in $\mathrm{F} 3 \mathrm{Hm} v \operatorname{tg} 1-\mathrm{KO}$ female liver,

124 representing a significant decrease in levels of these transcripts compared to $\mathrm{Ht}$, wt and Wt females

$125(\mathrm{p}<0.05)$. Levels of $v \operatorname{tg} 6$ and $v \operatorname{tg} 7$ transcripts were still detectable, with $v \operatorname{tg} 7$ transcript levels being

126 significantly higher ( $\sim 3$-fold) in Hm vtgl-KO female liver as compared to Wt female liver ( $<<0.05)$. The

$127 v \operatorname{vtg} 1$-KO had no significant effect on $v \operatorname{tg} 2$ and $v \operatorname{tg} 3$ expression (Fig 4, Panel A). No $v \operatorname{tg} 3$ transcripts were

128 detected in $\mathrm{F} 3 \mathrm{Hm} v \operatorname{tg} 3-\mathrm{KO}$ female livers, representing a significant decrease in vtg3 transcript levels

129 compared to $\mathrm{Ht}$, wt and $\mathrm{Wt}$ females $(\mathrm{p}<0.05)$. The $\mathrm{F} 3 \mathrm{Hm} v \operatorname{tg} 3-\mathrm{KO}$ females showed a statistically 
130 significant $\sim 3$-fold increase in hepatic $v \operatorname{tg} 7$ transcript levels relative to $\mathrm{Wt}$ fish $(\mathrm{p}<0.05)$. No significant 131 effect of $v \operatorname{tg} 3-\mathrm{KO}$ on expression of other $v \operatorname{tg}$ genes was observed (Fig 4, Panel B).

132 The relative abundances of individual Vtgs or of their product yolk proteins in liver and eggs, 133 respectively, of F3 $\mathrm{Hm} v \operatorname{tg} 1$-KO females were evaluated as normalized spectral counts (N-SC) from LC-

$134 \mathrm{MS} / \mathrm{MS}$ and revealed no detectable amount of $\operatorname{Vtg} 1,4$ and $5(\mathrm{p}<0.05)$ (Fig $\mathbf{5 A})$. Similar to gene 135 expression levels in these same samples, Vtg6 and 7 protein levels were still detectable and the Vtg7 136 levels were significantly higher in $\mathrm{Hm} v \operatorname{tg} 1$-KO female liver and eggs than in corresponding samples

137 from Wt females. $(\mathrm{p}<0.05)$. The relative abundance of $\mathrm{Vtg} 7$ protein was $\sim 4$-fold and $\sim 3$-fold higher in $138 \mathrm{Hm} v \operatorname{tg} 1-\mathrm{KO}$ liver and eggs, respectively, than in Wt females. Additionally, even though they were 139 uniformly low, $\mathrm{Vtg} 3$ protein levels were also significantly higher ( 2-fold) in $\mathrm{Hm} v \operatorname{tg} 1$-KO eggs than in 140 Wt eggs $(\mathrm{p}<0.05)($ Fig 5A).

141 The vtg3-KO resulted in the absence of detectable Vtg3 protein in both liver and eggs of F3 Hm 142 vtg3-KO females $(\mathrm{p}<0.05)$ but it did not seem to influence the relative abundances of $\operatorname{Vtg} 1,2,4,5$, and 6 143 or their yolk protein products in these samples (Fig 5B). However, Vtg7 protein levels were significantly

144 higher $(\sim 1.5$-fold $)$ in $v$ tg $3-\mathrm{KO}$ eggs than in Wt eggs $(\mathrm{p}<0.05)$, but $v \operatorname{tg} 3-\mathrm{KO}$ did not significantly alter the

145 relative abundance of $\operatorname{Vtg} 7$ protein in the liver of the egg donors, although average levels were higher for

146 the $v \operatorname{tg} 3-\mathrm{KO}$ fish (Fig 5 Panel B). For $v \operatorname{tg} 1-\mathrm{KO}, v \operatorname{tg} 3-\mathrm{KO}$ and Wt females, relative protein abundances of 147 all detected Vtgs were generally lower in liver in comparison to eggs. Among the various forms of Vtg 148 protein, their relative abundance in eggs from Wt females ranged from 15 to 31 times higher than in livers 149 of the same fish.

150 Domain-specific, affinity purified polyclonal antibodies were developed in rabbits against 151 zebrafish (zf) Vtg Type-specific epitopes (Type-I Vtg: NEDPKANHIIVTKS on LvH1; Type-III Vtg:

152 AQKDDIEMIVSEVG on LvL3. See Fig 2). The antibodies were used to detect these proteins by Western

153 blotting in the respective $\mathrm{Hm} v \operatorname{tg}-\mathrm{KO}, \mathrm{Ht}$ and $\mathrm{Wt}$ female livers, ovaries and eggs. The rabbit anti-zfLvH1

154 antibody revealed the presence of high molecular weight bands corresponding in mass to LvH1 in all 155 tested individuals and tissues (data not shown), consistent with the reported escape of the vtg6 and vtg7 
156 from Cas9 editing and the presence of Vtg6 and Vtg7 protein in liver, ovary and eggs from all groups of

157 fish in the vtgl-KO experiment ( $\mathrm{Hm}, \mathrm{Ht}$ and $\mathrm{Wt})$. In Western blots performed using anti-zfLvL3 in the

$158 v \operatorname{vtg} 3-\mathrm{KO}$ experiment, the antibody detected mainly a bold $\sim 24 \mathrm{kDa}$ band in samples of both ovary and

159 eggs from Ht and Wt fish, but not from Hm fish, very close to the deduced mass of the LvL3 polypeptide

160 (21.3 kDa) (Yilmaz et al., 2018) (Fig 6). The distinct absence of this $\sim 24 \mathrm{kDa}$ band only in samples of

161 Hm ovary and eggs is considered to be evidence of successful vtg3-KO in this experiment. The very bold

$162 \sim 68 \mathrm{kDa}$ band also present in samples of ovary and eggs from $\mathrm{Ht}$ and $\mathrm{Wt}$ females, but absent in samples

163 from $\mathrm{Hm} v \operatorname{tg} 3-\mathrm{KO}$ fish, which have a faint band in this position, may represent a degradation product of

164 intact, covalently linked LvH-LvL conjugate (Vtg3) persisting after maturational proteolysis, as has been

165 described for several species (Reading et al., 2009). Faint high molecular weight bands mainly $\geq 68 \mathrm{kDa}$

166 were also evident for samples of liver, ovary and eggs from all groups of fish in the vtg3-KO experiment

167 (Hm, Ht and $\mathrm{Wt}$ ). For $\mathrm{Hm} v \operatorname{tg} 3-\mathrm{KO}$ fish these bands are taken to indicate slight cross-reactivity of the

168 antibody with yolk proteins other than LvL3 under the experimental conditions employed. For the

169 corresponding $\mathrm{Ht}$ and Wt fish, some of these bands may represent high molecular weight Vtg3 products

170 bearing intact or partially degraded LvL3, as noted above. No bands specific to $\mathrm{Ht}$ and Wt fish were

171 detected in Western blots of liver performed using this antibody, consistent with absence of significant

172 quantities of Vtg3 protein detectable in Wt liver by LC-MS/MS (Fig 5), a commonly observed

173 phenomenon (see Yilmaz et al. (2016)) suggesting that Vtg3 is rapidly released into the bloodstream after

174 synthesis.

175 Phenotypic parameters including fecundity (number of eggs per spawn), egg fertilization,

176 hatching and survival rates, and egg diameter (embryo and chorion diameter) as well as larval size at 8

177 days post spawning (dps), were measured to detect potential effects of $v t g \mathrm{KO}$ on zebrafish reproductive

178 performance and development. There were no significant differences between $\mathrm{Hm} v \operatorname{tg} 1-\mathrm{KO}$ and Wt eggs

179 or offspring in fertilization rate, embryo size or larval size, respectively (Fig 7). However, F3 Hm vtg1-

$180 \mathrm{KO}$ females produced significantly more eggs per spawn $(593 \pm 40.06$, mean $\pm \mathrm{SEM})$ than did Wt

181 females $(280 \pm 28.97)(\mathrm{p}<0.05)$, although the final hatching rate of these eggs at $10 \mathrm{dps}(64.9 \pm 6.45 \%)$ 
182 was significantly lower than for eggs from Wt females $(99.6 \pm 0.24 \%)(\mathrm{p}<0.05)$. Eggs from F3 Hm $v \operatorname{tg} 1$ -

183 KO females also were strikingly delayed in hatching, completing hatching at 9 dps versus 5 dps for

184 control fish (Fig 7). It was noted that the Hm vtg1-KO embryos appeared to have weaker heartbeats and

185 body movements during incubation antecedent to hatching as compared to vtg3-KO embryos, which, even

186 with malformations, exhibited apparently normal heartbeat rhythms and body movements comparable to

187 those seen in Wt embryos. Embryo and larval survival rates of Hm vtgl-KO offspring were also

188 significantly lower than for Wt offspring, beginning from 5 dps when their mean survival rate was 57.14

$189 \pm 7.34 \%$ compared to $79.40 \pm 5.75 \%$ for Wt fish. The survival rate of Wt offspring changed little

190 thereafter, whereas the survival rate of Hm vtgl-KO offspring continued to decline, with $v \operatorname{tg} 1$-KO being

191 completely lethal to the larvae by 16 dps (Fig 8).

192 There were no significant differences between $\mathrm{Hm} v \operatorname{tg} 3-\mathrm{KO}$ fish and Wt fish in fecundity,

193 embryo size or larval size (Fig 7). However, the fertility, hatching rate and overall survival of $\mathrm{Hm} v \operatorname{tg} 3-$

194 KO eggs and offspring, respectively, were significantly less than seen in Wt fish $(\mathrm{p}<0.05)($ Fig 7$)$. The

195 fertilization rate of eggs from $\mathrm{F} 3 \mathrm{Hm} v \operatorname{tg} 3-\mathrm{KO}$ females $(35.5 \pm 7.7 \%)$ was substantially lower than for $\mathrm{Wt}$

196 eggs $(81.6 \pm 7.0 \%)$, although hatching of eggs from these females was only slightly delayed, and to a

197 much lesser extent than was observed for eggs from the F3 Hm vtgl-KO females (see below). The final

198 hatching rate for eggs obtained from F3 $\mathrm{Hm} v \operatorname{tg} 3-\mathrm{KO}$ females was $74.3 \pm 7.7 \%$ at 10 dps compared to

$19999.6 \pm 0.24 \%$ for Wt eggs (Fig 7). Embryo and larval survival rates of $\mathrm{Hm} v t g 3-\mathrm{KO}$ offspring were

200 significantly less than for Wt offspring $(\mathrm{p}<0.05)$, beginning from 8 hours post spawning (hps), with the

201 difference from Wt fish increasing throughout the $22 \mathrm{~d}$ experiment (Fig 8). As previously reported

202 (Yilmaz et al., 2017), at 2-4 hps eggs from low fertility spawns have a high incidence of abnormal

203 embryos with asymmetric cell cleavage and/or developmental arrest at early cleavage stages. Such

204 embryos may survive to 8 hps but not to 24 hps. The larval survival rate for $\mathrm{Hm} v \operatorname{tg} 3-\mathrm{KO}$ offspring was

205 only $6.25 \pm 1.6 \%$ at 22 dps compared to $69.2 \pm 3.8 \%$ for Wt offspring (Fig 8).

206 Separate panels in Fig 9 illustrate morphological disorders observed during development of F4

$207 \mathrm{Hm} v \operatorname{tg} 1-\mathrm{KO}$ and $\mathrm{Hm} v \operatorname{tg} 3-\mathrm{KO}$ fish in comparison to offspring from Wt females at 4 and 8 dps. In Hm 
$v \operatorname{tg}$-KO fish, these phenotypic disorders mainly involved pericardial and yolk sac/abdominal edema accompanied by spinal lordosis evidenced as curved or bent back deformities. The severity of these

210 malformations, mainly the pericardial and yolk sac edema, appeared to be relatively lower in $\mathrm{Hm} v \operatorname{tg} 1-$

$211 \mathrm{KO}$ fish than in $\mathrm{Hm} v \operatorname{tg} 3-\mathrm{KO}$ fish. However, the prevalence of deformity was much greater for Hm $v \operatorname{tg} 1-$

$212 \mathrm{KO}$ fish, with nearly all larvae exhibiting some deformity versus approximately $30 \%$ of $\mathrm{Hm} v \operatorname{tg} 1$-KO

213 larvae. Finally, the Hm vtgl-KO larvae exhibited no feeding activity or motor activities comparable to

214 those seen in $\mathrm{Hm} v \operatorname{tg} 3-\mathrm{KO}$ and $\mathrm{Wt}$ fish at the same times.

\section{DISCUSSION}

Vitellogenins are the 'mother proteins' that supply most yolk nutrients supporting early vertebrate

219 development, and most species have evolved multiple forms of Vtg. However, little is known about

220 specific functions of these different forms of Vtg and it is uncertain which forms are essential for

221 successful development or at what stage(s) of development they are required. The present research was

222 undertaken to address these questions using a zebrafish CRISPR/Cas9 vtg gene KO model. Three out of

223 five type-I zebrafish $v \operatorname{tg}$ genes ( $v \operatorname{tg} 1,4$ and 5) were knocked out simultaneously (vtgl-KO experiment),

224 and the type-III $v \operatorname{tg}$ gene (vtg3) was knocked out individually (vtg3-KO experiment), and the effects on

225 maternal reproductive physiology and offspring development and survival were evaluated.

226 The efficacy of CRISPR/Cas9, which is reported to be the most practical and efficient tool

227 available for genome editing, was lower in the vtgl-KO experiment (20\%), where five genes were

228 targeted concomitantly, than in the $v \operatorname{tg} 3-\mathrm{KO}$ experiment $(80 \%)$ where only a single gene was targeted.

229 Since the site-specific cleavage efficiency is mostly dependent on the concentrations of single guide (sg)

230 RNAs and Cas9 endonuclease, Liu et al. (2018) related the low efficiency of simultaneous knockout of

231 multiple homologous genes to the fact that more sgRNAs and gene target sites share the same Cas9

232 enzyme. In addition to low efficiencies in the $v \operatorname{tg} 1-\mathrm{KO}$ experiment, the escape of the type-I $v \operatorname{tg} 6$ and $v \operatorname{tg} 7$

233 from Cas9 editing might be simply an outcome of an insufficient amount of administered Cas9 RNA. 
234 Attempts at optimization of sgRNA/Cas9 concentrations may be useful in future studies. Taking into

235 account the syntenic organization and close proximity of type-I vtg genes in zebrafish (Yilmaz et al.,

236 2018), and the identity (100\%) of the common target sites for these genes, it is difficult to postulate

237 criteria upon which any preference of Cas9 activity might be directed. No matter which gene-editing tool

238 is used, low efficiency of germline mutant transmission has been a commonly faced problem among

239 researchers, usually leading to labor intensive and time consuming screening work to acquire high-

240 throughputs (Xie et al., 2016). The low ratios of mutation transmission to next generations in the present

241 study $(0.01 \%-0.025 \%)$ emphasize the need for further research to improve germline transmission

242 efficiencies in genome editing. Production of stable mutant lines was delayed an extra generation in both

243 the $v \operatorname{tg} 1-\mathrm{KO}$ and $v \operatorname{tg} 3-\mathrm{KO}$ experiments since no mutation-positive female founders were obtained at the

244 F1 generation for performing subsequent reproductive crosses.

245 The incapacitation of $v \operatorname{tg} 1, v \operatorname{tg} 4$, and $v \operatorname{tg} 5$ in the $v \operatorname{tg} 1-\mathrm{KO}$ experiment, and of $v \operatorname{tg} 3$ in the $v \operatorname{tg} 3-\mathrm{KO}$

246 experiment, was confirmed by conventional PCR, agarose gel electrophoresis and sequencing of gDNA

247 and also by relative quantification of corresponding $v t g$ transcript and Vtg protein abundances via qPCR

248 and LC-MS/MS, respectively, with the absence of $\mathrm{Vtg} 3$ in $\mathrm{Hm}$ vtg3-KO ovary and eggs being

249 additionally confirmed by Western blotting. Collectively, these procedures provided strong evidence of

250 the success of genome editing and $v t g$ gene KO. The introduced mutations were all large deletions (1182-

$2511281 \mathrm{bp}$ ) that were achieved by administration of multiple sgRNAs. By disturbing the structure of the

$252 \mathrm{LvH}$ chain in both the $v \operatorname{tg} 1-\mathrm{KO}$ and $v \operatorname{tg} 3-\mathrm{KO}$ experiments via the creation of large gaps in the respective

253 LvH polypeptides, it was expected that the mutant proteins would not fold properly, or be able to bind to

254 their receptor in the case of $\mathrm{Vtg} 3$, even if they were produced and partly expressed by the liver. There

255 were no signs of hepatic synthesis of $\mathrm{Vtg} 1,4$ or 5 in $\mathrm{Hm} v \operatorname{tg} 1-\mathrm{KO}$ individuals or of $\mathrm{Vtg} 3$ in $\mathrm{Hm} v \operatorname{tg} 3-\mathrm{KO}$

256 liver. While detection of the $v \operatorname{tg} 6$ and $v \operatorname{tg} 7$ transcripts and their product proteins was expected in the $v \operatorname{tg} 1-$

257 KO experiment, since these two type-I vtg genes escaped Cas9 editing, the strikingly high abundance of

$258 \mathrm{Vtg} 7$ (but not Vtg6) at both transcript and protein levels in both $\mathrm{Hm} v \operatorname{tg} 1-\mathrm{KO}$ and $\mathrm{Hm}$ vtg3-KO

259 individuals (Figs 4 and 5) was unexpected. These observations suggest an attempt of the organism to 
compensate for the loss of other types of Vtgs by augmentation of Vtg7 levels, and they imply the

261 existence of heretofore-unknown mechanisms for regulating Vtg homeostasis.

The lack of a mutant phenotype in Hm mutant individuals due to compensatory gene expression triggered upstream of protein function is known as 'genetic compensation' and this phenomenon has been

264 encountered in gene editing studies of a wide range of model organisms. As examples, Marschang et al.

265 (2004) related the normal development and lack of mutant phenotypes in LDL receptor-related protein $1 \mathrm{~b}$

266 (LRP1b)-deficient mutant mice to functional compensation by LRP1, and Sztal et al. (2018) found that a

267 genetic actin1b (actc1b) zebrafish mutant exhibits only mild muscle defects and is unaffected by injection

268 of an actc1b-targeting morpholino due to compensatory transcriptional upregulation of an actin paralog in

269 the same fish. In the present study, compensatory increases in relative levels of total Vtg protein

270 attributable to upregulation of $\mathrm{Vtg} 7$ protein in $\mathrm{F} 4 \mathrm{Hm} v \operatorname{tg} 1-\mathrm{KO}$ eggs offset only about half of the decrease

271 in total Vtg protein attributable to KO of $v \operatorname{tg} 1,4$ and 5 (Fig 5A). Therefore, these eggs/offspring were still

272 deficient of type-I Vtg protein and they uniformly exhibited mutant and ultimately lethal phenotypes,

273 perhaps due to the insufficient compensation. In contrast, the compensatory increase in total Vtg protein

274 attributable to upregulation of $\mathrm{Vtg} 7 \mathrm{in} \mathrm{Hm} v \operatorname{tg} 3-\mathrm{KO}$ eggs was several-fold greater than the loss of $\mathrm{Vtg}$

275 protein attributable to $v \operatorname{tg} 3 \mathrm{KO}$ (Fig 5B), yet many of these eggs/offspring still exhibited mutant

276 phenotypes, with egg fertility being very low (see below) and most offspring not surviving for $22 \mathrm{~d}$ of

277 development. Nonetheless, the incidence of mutant phenotypes in Hm vtg3-KO larvae (30\%) was far less

278 than in $\mathrm{Hm} v \operatorname{tg} 1-\mathrm{KO}$ larvae, all of which were malformed, and a low percentage $(6.25 \%)$ of $\mathrm{Hm} v \operatorname{tg} 3-\mathrm{KO}$

279 larvae did survive for $22 \mathrm{~d}$ post fertilization, whereas no $\mathrm{Hm}$ vtg1-KO larvae did. These observations

280 indicate that, while it is possible that upregulation of $\mathrm{Vtg} 7$ may have mitigated to some extent the effects

281 vtg3 KO owing to decreased total Vtg protein, Vtg7 cannot fully substitute for Vtg3 or eliminate the

282 adverse effects of $v \operatorname{tg} 3 \mathrm{KO}$ on egg fertility and offspring development. Therefore, Vtg3 must have

283 functional properties distinct from Vtg7 and perhaps other type-I Vtgs.

284 Transcription of $v t g$ genes is initiated when estrogen (E2)/estrogen receptor (Esr) complexes bind

285 to estrogen response elements (ERE) located in the gene promoter regions (Babin, 2008; Nelson and 
Habibi, 2013). E2-Esr complexes can also be tethered to transcription factor complexes targeting binding sites distinct from EREs, and several transcription factors other than Esrs have binding sites located in promoter regions of zebrafish vtg genes (reviewed by Lubzens et al., 2017). There is evidence that the multiple $v t g$ genes in zebrafish exhibit differential sensitivities to estrogen induction as well as disparate patterns of ERE and other transcription factor binding sites in their promoter regions (Levi et al., 2009,

291 2012). Bioinformatics analyses indicated that the promoter region of $v \operatorname{tg} 7$ is comparatively rich in binding

292 sites for transcription factors involved in retinoic acid signaling such as retinoic acid response elements

293 (RAREs), and peroxisome proliferator-activated receptors (PPARs)/ retinoid X receptor (RXR), while

294 having only a single ERE (most other vtgs having 2-3) (see Levi et al., 2012 Table 3). These types of

295 differences between $v \operatorname{tg}$ promoters could underpin selective upregulation of $\mathrm{Vtg} 7$ in response to ablation

296 of other forms of Vtg (other type-I Vtgs, Vtg3) via gene KO. Conspecific Vtg (type not specified) has

297 been shown to downregulate plasma levels of E2 in vivo when injected into vitellogenic rainbow trout

298 (Oncorhynchus mykiss) (Reis-Henriques et al., 1997) and to inhibit steroidogenesis leading to E2

299 production in vitro by ovarian follicles of rainbow trout (Reis-Henriques et al., 1997, 2000) and greenback

300 flounder, Rhombosolea tapirina (Sun and Pankhurst, 2006). Partial release from such inhibition in vtg-

301 KO fish would increase vitellogenic signaling to the liver, activating estrogen responsive genes including 302 those encoding Vtgs, Esr (Esrs) and PPARs.

304 Vtgs have been shown to upregulate vitellogenesis in Indian walking catfish (Clarias batrachus) (Juin et

305 al., 2017; Bhattacharya et al., 2018) and comparisons of the available deduced catfish Vtg polypeptide 306 sequences (85 and 152 residues; Juin et al., 2017, Fig. 3) to Vtgs from zebrafish and other teleosts using

307 CLUSTAL W and BLASTP (data not shown) indicate that they are forms of VtgAol showing a high 308 identity to type-I zebrafish Vtgs (up to $80 \%$ with $V \operatorname{tg} 7$ ). The specific mechanism(s) by which $V \operatorname{tg} 7$ is 309 preferentially upregulated in $v \operatorname{tg}$-KO zebrafish, and special properties of $\mathrm{Vtg} 7$ for regulation of $\mathrm{Vtg}$

310 homeostasis, are meaningful subjects for future research. Levels of Vtg3 protein were also upregulated in

311 eggs from F3 Hm vtgl-KO females (Fig 5A) but the significance of this increase is difficult to interpret as 
312 it was too slight to have much impact on total Vtg levels, and because hepatic levels of $v \operatorname{tg} 3$ transcripts

313 and of $\mathrm{Vtg} 3$ protein were not elevated in these fish (Figs $4 \mathbf{A}$ and $\mathbf{5 A}$ ). Transcripts of $v \operatorname{tg} 3$ are reported to

314 be the most intensely upregulated transcripts in vitellogenic female and estrogenized male zebrafish (Levi

315 et al., 2009) and there may not have been scope for further increases in the vtgl-KO fish. In this case post-

316 transcriptional mechanisms for upregulating Vtg3 could have been at play (Flouriot et al., 1996; Ren et

317 al., 1996). As noted above, Vtg3 may be released into the bloodstream immediately after synthesis, which

318 would explain the lack of significant quantities of this protein in livers of $\mathrm{Hm} v \operatorname{tg} 1-\mathrm{KO}$ and Wt fish (Fig

319 5).

320 Neither vtg1-KO nor vtg3-KO influenced egg, embryo or larval size in spawns producing F4

321 offspring of the stable mutant lines (Fig 7), and there were no apparent differences in ovary structure

322 among the different groups of maternal F3 females (Hm, Ht, wt and $\mathrm{Wt}$ ) sampled after spawning (data

323 not shown). However, F3 Hm vtgl-KO females exhibited a 2-fold increase in fecundity (egg production)

324 relative to $\mathrm{Wt}$ females, with normal egg fertility equivalent to that of $\mathrm{Wt}$ females (Fig 7 ). This response to

325 elimination of three type-I Vtgs (including the most abundant one, Vtg1) implies that one or more of

326 these Vtgs are normally involved in restriction of fecundity, perhaps via the aforementioned inhibition of

327 follicular estrogenesis. It is also possible that $\mathrm{Vtg} 7$, which was highly elevated in $\mathrm{Hm} v \operatorname{tg} 1-\mathrm{KO}$ females,

328 might somehow positively modulate fecundity. The referenced VtgAol of walking catfish, when pelleted

329 and implanted into pre-vitellogenic females, has been shown to stimulate vitellogenesis and complete

330 oocyte growth all the way through the transition to final maturation (Bhattacharya et al., 2018). In the

331 final analysis, any 'compensation' by Vtg7 for loss of other type-I Vtgs must be deemed ineffectual, as

332 the resulting embryos unconditionally exhibited serious and lethal developmental abnormalities (see

333 below).

334 The vtg-KO zebrafish larvae exhibited major phenotypic disorders, mainly pericardial and yolk

335 sac/abdominal edemas and spinal lordosis associated with curved or arched back deformities. These

336 abnormalities were observed to be much less prevalent, albeit usually more severe, in vtg3-KO larvae, but

337 present to some extent in all $v \operatorname{tg} 1-\mathrm{KO}$ larvae along with the noted behavioral differences. Skeletal axis 
malformations and pericardial and yolk sac/abdominal edema are among the most common deformities observed in cultured teleosts and they form an interrelated cluster of abnormalities that tend to be observed together (Alix et al., 2017). For example, in zebrafish pericardial edema tends to precede

341 development of yolk sac edema, which when severe leads to notochord deformation (see Hanke et al.,

342 2013, Fig. 1). These abnormailites have been associated with a broad variety of conditions including, as

343 examples, rearing systems for Eurasian perch, Perca fluviatilis (Alix et al., 2017), larval rearing

344 temperatures for Atlantic halibut, Hippoglossus hippoglossus L. (Ottesen and Bolla, 1998), embryo

345 cryopreservation practices for streaked prochilod, Prochilodus lineatus (Costa et al., 2017), and, in

346 zebrafish, phenanthroline toxicity (Ellis and Crawford, 2016), influenza A virus infection (Gabor et al.,

347 2014), knockdown or KO of genes related to kidney function or development, respectively (Hanke et al.,

348 2013; Zhang et al., 2018), knockdown of the wwox tumor suppressor gene (Tsuruwaka et al., 2015),

349 deletion of a gene ( $p r 130$ ) encoding a protein essential for myocardium formation and cardiac contractile

350 function (Yang et al., 2016), and mutagenesis of genes involved in thyroid morphogenesis and function

351 (Trubiroha et al., 2018), among others. The edemas may ultimately result from many different proximal

352 causes such as cardiac, kidney, liver or osmoregulatory failure, and researchers are just beginning to

353 develop screens to differentiate between them (Hanke et al., 2013). Although they can occur under many

354 different conditions and arise via several possible mechanisms, these major mutant phenotypes observed

355 in the present study were not encountered in control Wt offspring and, therefore, they are clearly related 356 to deficiencies of type-I Vtgs (Vtg1, 4 and 5) and of Vtg3.

357 Embryo and larval survival rates were severely diminished by $v t g$ gene KO, but the magnitude,

358 type and timing of losses differed between $v \operatorname{tg} 1-\mathrm{KO}$ and $v \operatorname{tg} 3-\mathrm{KO}$ fish (Fig 8). The fertility of $\mathrm{Hm} v \operatorname{tg} 3-$

359 KO eggs was only half that observed in Wt eggs (Fig 7), indicating that Vtg3 is an important contributor

360 to fertility in zebrafish. Among the Vtgs examined, this dependency was specific to Vtg3, since fertility

361 was not 'rescued' by the increase in $\mathrm{Vtg} 7$ levels in $\mathrm{Hm} v \operatorname{tg} 3-\mathrm{KO}$ eggs, which was far greater than normal

362 Vtg3 levels in Wt fish (Fig 5B), and this adverse effect on fertility was not seen in Hm vtgl-KO eggs.

363 The substantial losses of $\mathrm{Hm} v \operatorname{tg} 3-\mathrm{KO}$ eggs began early, at only $8 \mathrm{hps}$, and less than 30\% survived to 24 
364 hps (Fig 8). Both vtgl-KO and Wt eggs showed significant but much fewer losses $(\mathrm{p}<0.05)$ during this

365 same interval. In this study, fertility was estimated conservatively, based on numbers of viable embryos

366 showing normal cell division and subsequently developing to $\sim 24 \mathrm{hps}$. It is uncertain whether the high

367 mortality of $\mathrm{Hm} v \operatorname{tg} 3-\mathrm{KO}$ eggs between 8 and 24 hps (Fig 8) resulted from a failure to be fertilized or

368 from defects in early development involving zygotes that fail to initiate cell division or that briefly

369 undergo abnormal cell divisions and then die. In future studies, some Hm mutant and Wt females should

370 be bred with males bearing a unique germline marker gene, such as vasa::egfp (Krøvel and Olsen, 2002),

371 that can be genotyped in resulting eggs and embryos to resolve this question.

372 The mechanism(s) whereby Vtg3 deficiency impairs fertility and/or early development of

373 zebrafish are unknown. A recent study examining the proteomics of egg/embryo developmental

374 competence in zebrafish identified disruption of normal oocyte maturation, including maturational

375 proteolysis of Vtgs, as a likely cause of poor egg quality (Yilmaz et al., 2017). The proteolysis of Vtgs by

376 cathepsins during oocyte maturation, a phenomenon that has been observed in zebrafish eggs undergoing

377 maturation in vitro (Carnevali et al., 2006), releases FAA that steepen the osmotic gradient driving water

378 influx through aquaporins on the cell surface, leading to oocyte hydration (Cerdà et al., 2007, 2013).

379 These FAA are also major substrates for aerobic energy metabolism during early embryogenesis (Thorsen

380 and Fyhn, 1996; Finn and Fyhn, 2010). In some species, Vtg3 (VtgC) is subjected to maturational

381 proteolysis (see Yilmaz et al., 2016) and it is possible that zebrafish Vtg3 contributes to these critical

382 processes ongoing during oocyte maturation, which are required for production of viable eggs. However,

383 mass balance considerations seem to exclude the possibility that the early mortality of $\mathrm{Hm} v \operatorname{tg} 3-\mathrm{KO}$

384 embryos results substantially from nutritional deficiencies. In this and prior studies of zebrafish, Vtg3 has

385 been shown to be a very minor form of Vtg making only a miniscule contribution to stores of Vtg-derived

386 yolk proteins in eggs (Fig 5; see also Yilmaz et al., 2018). Nonetheless, Vtg3 is clearly an important, if

387 not essential, contributor to fertility and/or early development in zebrafish. The continuous mortality of

$388 \mathrm{Hm}$ vtg $3-\mathrm{KO}$ embryos after $24 \mathrm{hps}$, leading to only $\sim 6 \%$ survival at $22 \mathrm{dps}$, suggests that Vtg3 also

389 contributes to late embryonic and larval development, as suggested in several prior studies (see below). 
$391(\sim 70 \%)$ but decreased continuously thereafter, becoming significantly less than survival of Wt embryos

392 by $5 \mathrm{dps}$, and then decreasing to zero by $16 \mathrm{dps}$ (Fig 8). The collective absence of $\operatorname{Vtg} 1,4$ and 5 in 393 zebrafish is lethal to offspring, and this effect could not be rescued via genetic compensation by Vtg7 or

394 offset by the remaining intact Vtgs. This finding is not surprising as, collectively, these 3 type-I Vtgs

395 account for the vast majority of Vtg-derived protein in Wt zebrafish eggs (Fig 5; see also Yilmaz et al.,

396 2018). Since most mortality of $v \operatorname{tg} 1-\mathrm{KO}$ offspring occurred relatively late in development in larvae, with

397 mortality rate increasing after $10 \mathrm{dps}$ when yolk sac absorption was being completed (Fig 8), the

398 collective contributions of $\mathrm{Vtg} 1,4$ and 5 to survival could be largely nutritional, although this remains to

399 be verified.

400 It is evermore apparent that the different types of vertebrate Vtg can have dissimilar effects on

401 reproductive processes. As noted above (see also Introduction), in marine acanthomorphs spawning

402 pelagic eggs in seawater the different types of Vtg can play disparate roles in oocyte hydration,

403 acquisition of egg buoyancy, and early versus late embryonic and larval nutrition (Matsubara and Koya,

404 1997; Matsubara et al., 1999, 2003; Reith et al., 2001; Sawaguchi et al., 2005, 2006a, 2006b; Finn, 2007).

405 The type-specific ratios of circulating Vtgs (e.g. VtgAa:VtgAb:VtgC) may vary considerably during

406 oocyte growth, but ratios of their derived yolk protein products present in eggs tend to be fixed and

407 characteristic of species (Hiramatsu et al., 2015; Reading et al., 2017). This is also the case in zebrafish

408 as evidenced by the similarity of Vtg profiles by type (and subtype) in Wt fish in the $v \operatorname{tg} 1-\mathrm{KO}$ and $v \operatorname{tg} 3-$

$409 \mathrm{KO}$ experiments, and also in comparison to Wt fish in an earlier study (Yilmaz et al., 2018). It is thought

410 that Vtg type-specific ratios of yolk proteins in eggs are maintained via activity of selective receptors for

411 each type of $\mathrm{Vtg}$, which target their specific ligand(s) into different compartments where their yolk

412 protein products undergo disparate degrees of proteolysis during oocyte maturation. The initial abundance

413 and degree of proteolysis of the yolk proteins determines their relative contribution(s) to oocyte

414 hydration, egg buoyancy, FAA nutrition of early embryos and lipoprotein nutrition for late stage larvae

415 (Hiramatsu et al., 2015; Reading et al., 2017). The collective findings of the present study introduce a new 
416 point of view on the roles that multiple vitellogenins can play in vertebrate reproduction. Distinctively

417 from what has been reported previously, the present study presents a mixed model of Vtg functionality

418 covering both maternal reproductive physiology and early development of offspring, where type-I Vtgs

419 regulate fecundity and make essential contributions to embryonic morphogenesis, hatching and larval

420 kinesics and survival (Vtg1, 4 and 5), and also provide some homeostatic regulation of total Vtg levels

421 (Vtg7), while Vtg3 (a typical VtgC) is critically important to fertility and early embryogenesis and also

422 influences later development.

423 In summary, the present study, for the first time, targeted multiple forms of Vtgs for KO at

424 family level using CRISPR/Cas9 technology in the zebrafish, a well-established biomedical model. The

425 collective knock out of $v \operatorname{tg} 1,4$, and 5 and the individual knock out of $v \operatorname{tg} 3$ were achieved successfully. A

426 compensatory increase in $v \operatorname{tg} 7$ at both transcript and protein levels was observed in both types of $v \operatorname{tg} \mathrm{KO}$

427 mutants. However, this compensation was not effective in rescuing the serious developmental

428 impairments and high mortalities resulting from ablation of three other type-I Vtgs or of Vtg3. By far the

429 most abundant forms of Vtg in zebrafish, the type-I Vtgs appear to have essential developmental and

430 nutritional functions in both embryos and larvae. In spite of being a very minor form of Vtg in zebrafish

431 and most other species, and also the most divergent form, Vtg3 contributes importantly to the

432 developmental potential of zygotes and/or early embryos. Finally, Vtgs appear to have previously

433 unreported regulatory effects on the physiology of maternal females, including limitation of fecundity

434 (type-I Vtgs) and maintenance of fertility (Vtg3). These novel findings represent the first steps toward

435 discovery of the specific functions of multiple vertebrate Vtgs via genome editing. Further physiological

436 studies are necessary to pinpoint the exact molecular mechanisms disturbed in the vtg mutants.

\section{MATERIAL AND METHODS}

\section{$441 \quad$ 4.1. Animal care, spawning and phenotypic observations}


443 (Germany) were obtained from our zebrafish facility (INRA UR1037 LPGP, Rennes, France). The fish

444 were $\sim 15$ months of age and of average length $\sim 5.0 \mathrm{~cm}$ and average weight $\sim 1.4 \mathrm{~g}$. The zebrafish were

445 housed under standard conditions of photoperiod (14 hours light and 10 hours dark) and temperature (28

$446{ }^{\circ} \mathrm{C}$ ) in $10 \mathrm{~L}$ aquaria, and were fed three times a day ad libidum with a commercial diet (GEMMA,

447 Skretting, Wincham, Northwich, UK). Females were bred at weekly intervals to obtain egg batches for

448 CRISPR sgRNA microinjection (MI). The night before spawning, paired males and females bred from

449 different parents were separated by an opaque divider in individual aquaria equipped with marbles at the

450 bottom as the spawning substrate. The divider was removed in the morning, with the fish left undisturbed

451 to spawn. Egg batches in majority containing intact, clean looking, well defined, activated eggs at the 1-

452 cell stage were immediately transferred to microinjection facilities.

453 For phenotyping observations five couples formed from F3 Hm males and females and five Wt

454 couples were spawned from 3 to 8 times and embryonic development, survival rate, hatching rate, and

455 larval development were subsequently observed until 22 dps. Survival, fecundity and fertilization rate

456 data was collected from 21, 24 and 5 spawns from vtgl-KO, vtg3-KO and Wt couples, respectively.

457 Hatching rate was calculated based on the number of surviving embryos at $24 \mathrm{~h}$ and only spawns with $>5$

$458 \%$ survival rates were considered, therefore, hatching rate data was collected from 21,16 , and 5 spawns

459 from vtgl-KO, vtg3-KO and Wt couples, respectively, in this study. Fecundity (number of eggs per

460 spawn) was recorded immediately after spawning and collected eggs were incubated in $100 \mathrm{~mm}$ Petri

461 dishes filled with embryo medium (17.1 mM NaCl, $0.4 \mathrm{mM} \mathrm{KCl}, 0.65 \mathrm{mM} \mathrm{MgSO}_{4}, 0.27 \mathrm{mM} \mathrm{CaCl}_{2}$,

$4620.01 \mathrm{mg} / \mathrm{L}$ methylene blue) to assess embryonic development and phenotyping parameters. Incubated

463 eggs/embryos were periodically observed at the early blastula ( 256 cell) stage $(\sim 2-3 \mathrm{~h}$ post spawning

$464 \mathrm{hps}$ ), at mid-blastula transition stage ( $\sim 4 \mathrm{hps})$, at the shield to $75 \%$ epiboly stages ( $\sim 8 \mathrm{hps})$, at the early

465 pharyngula stage ( $\sim 24 \mathrm{hps}$ ), and during the hatching period at 48 and $72 \mathrm{hps}$ (long-pec to protruding-

466 mouth stages) following standard developmental staging (Kimmel et al., 1995). Fertilization rate was

467 calculated based on viable embryos showing normal cell division and subsequent development to $\sim 24$ hps 
468 since zygotes failing to initiate cell division, and embryos showing asymmetrical cell cleavage or early 469 developmental arrest were dead by then. As noted above (see Discussion) it is uncertain whether these 470 aberrant eggs/embryos result from infertility or developmental defects. The number of surviving

471 eggs/embryos was recorded, those not surviving were removed and the number of abnormal embryos was

472 recorded at each observation point. Hatched embryos were transferred into larger volume containers (1 L)

473 filled with standard $28^{\circ} \mathrm{C}$ culture water and were fed ad libitum with artemia and GEMMA weaning diet

474 mix after yolk sac absorption (at around $10 \mathrm{dps}$ ). At the time of feeding, larvae were also observed for

475 motor and feeding activities. Observations were made daily up to 22 dps. Subsamples of 10-12 embryos

476 and larvae from each clutch were taken for measurements of embryo and chorion diameter, and larval size

477 at 2-3 hps and $8 \mathrm{dps}$, respectively. Measurements were made using an ocular micrometer under a Zeiss

478 Stemi 2000-C stereomicroscope connected to a ToupCam 3,1 M pixels camera employing the Toupview

479 software.

\subsection{Single guide RNA (sgRNA) design, synthesis and microinjection}

483 common to all five genes were designed using CRISPR MultiTargeter (Prykhozhij et al., 2015) available

484 online at http://www.multicrispr.net. Of proposed candidates, three target regions located on exons 4,14

485 and 17, corresponding to the $\mathrm{LvH}$ yolk protein domain were chosen for the $\operatorname{vtg} 1$-KO experiment. The 486 vtg3 genomic region was separately submitted to online available target designer tool at 487 http://zifit.partners.org/ZiFiT/ChoiceMenu.aspx (Sander et al., 2007, 2010) and of proposed candidates, 488 three gene specific target regions located on exons 4, 6 and 11, corresponding to the LvH yolk protein 489 domain, were chosen. A schematic representation of the general strategy followed for CRISPR target 490 design is presented in Fig 1. Forward and reverse oligonucleotides matching the chosen target sequences

491 (given in S1 Table) were annealed and ligated to the pDR274 expression vector (Addgene). The vector 492 was subsequently linearized by the DraI restriction digestion enzyme (Promega) and in vitro transcribed 493 using mMessage mMachine T7 Transcription Kit (Ambion) according instructions from the manufacturer. 
494 The pCS2-nCas9n plasmid (Addgene Plasmid 47929) was digested with NotI restriction digestion 495 enzyme (Promega) and transcribed using mMessage mMachine SP6 Transcription Kit (Ambion)

496 according instructions from the manufacturer. The sgRNA concentration was measured on a Nanodrop

4971000 Spectrophotometer (Thermo Scientific, USA) and integrity was tested before use using an Agilent 498 RNA 6000 Nano Kit (Agilent) on an Agilent 2100 Bioanalyzer.

499 Approximately 100 eggs per batch were injected with sgRNA mix containing sgRNAs for three 500 target sites (at $\sim 30 \mathrm{ng} / \mathrm{ul}(=30 \mathrm{mM})$ in $20 \mathrm{ul}$ of the final mix each) and nCas9n RNA (at $\sim 200 \mathrm{ng} / \mathrm{ul}(=200$

$501 \mathrm{mM}$ ) in the final mix) at the one-cell stage in both the $v \operatorname{tg} 1-\mathrm{KO}$ and $v \operatorname{tg} 3-\mathrm{KO}$ experiments. A total of 120

502 pg sgRNA mix and $\sim 800$ pg Cas9 RNA was injected per embryo. Injected embryos were kept in $100 \mathrm{~mm}$

503 petri dishes filled with embryo medium (17.1 mM NaCl, $0.4 \mathrm{mM} \mathrm{KCl}, 0.65 \mathrm{mM} \mathrm{MgSO}, 0.27 \mathrm{mM}$

$504 \mathrm{CaCl}_{2}, 0.01 \mathrm{mg} / \mathrm{L}$ methylene blue) to assess microinjection efficiency, embryo survival and development

505 post injection.

\subsection{Genotyping by conventional PCR}

As representatives of their generation, ten embryos were sampled randomly and gDNA was

509 extracted individually and used as a template in targeted conventional PCR reactions to screen for

510 introduced mutations in the targeted $v t g$ genes. For this purpose, embryos surviving for $24 \mathrm{~h}$ post-

511 injection were incubated in $100 \mu 1$ of $5 \%$ Chelex ${ }^{\circledR} 100$ Molecular Biology Grade Resin (BioRad) and 50

$512 \mu \mathrm{l}$ of Proteinase K Solution (20 mg/ml, Ambion) initially for $2 \mathrm{~h}$ at $55{ }^{\circ} \mathrm{C}$ and subsequently for $10 \mathrm{~min} 99$

$513{ }^{\circ} \mathrm{C}$ with constant agitation at $12000 \mathrm{rpm}$. Extracts were then centrifuged at $5000 \mathrm{xg}$ for 10 minutes and

514 supernatant containing gDNA was transferred into new tubes and stored at $-20{ }^{\circ} \mathrm{C}$ until use.

515 To evaluate generational transfer of introduced mutations, genotyping of $\sim 2$ month old offspring 516 was conducted after extraction of gDNA from fin-clips. For this purpose, fish were anaesthetized in 2-

517 phenoxyethanol $(0.5 \mathrm{ml} / \mathrm{L})$ and part of their caudal fin was excised with a sterile scalpel. Genomic DNA

518 from fin tissues were then extracted using Chelex $5 \%$ as described above. 
One $\mu$ l ( $100 \mathrm{ng})$ of extracted gDNA was used in $20 \mu$ PCR reactions using AccuPrime ${ }^{\mathrm{TM}}$ Taq

520 DNA Polymerase, High Fidelity (Invitrogen) and 10x AccuPrime ${ }^{\mathrm{TM}}$ PCR Buffer II in combination with

521 gene specific primers (at $10 \mu \mathrm{M}$ each) anchoring target sites on the genomic sequence of targeted genes

522 (Fig 1). PCR cycling conditions were as follows; 1 cycle of initial denaturation at $94{ }^{\circ} \mathrm{C}$ for 2 min, 35

523 cycles of denaturation at $94{ }^{\circ} \mathrm{C}$ for $15-30 \mathrm{sec}$, annealing at $52-64{ }^{\circ} \mathrm{C}$ for $15-30 \mathrm{sec}$ and extension at $68{ }^{\circ} \mathrm{C}$

524 for $1 \mathrm{~min}$ per kb plus 1 cycle of final extension at $68{ }^{\circ} \mathrm{C}$ for $5 \mathrm{~min}$. Non-purified PCR products or gel

525 purified DNA were sequenced using gene specific primers indicated in S1 Table by the Eurofins

526 Genomics sequencing service (https://www.eurofinsgenomics.eu/). Obtained sequences were aligned to

527 corresponding zebrafish genomic sequence using Clustal Omega (Sievers et al., 2011) for characterization

528 and localization of introduced mutations, and then were blasted against all sequences available online

529 using NCBI nucleotide Blast (Blastn) (Altschul et al., 1990) for confirmation of the consistency, accuracy

530 and type of the mutations created at the target sites.

531

\subsection{Generation of pure zebrafish lines carrying the introduced mutations}

In both the vtg1-KO and $v \operatorname{tg} 3-\mathrm{KO}$ experiments, embryos carrying introduced mutations were

534 raised to adulthood, fin clipped and re-genotyped to confirm mutation of their type-I or III vtgs, and then

535 heterozygous ( $\mathrm{Ht}$; $v \operatorname{tg} 1+/-$ and $v \operatorname{tg} 3+/-)$ males with the mutation on a single allele were outcrossed with

536 non-related wild type $(\mathrm{Wt} ; \operatorname{vtg} 1+/+$ and $v \operatorname{tg} 3+/+)$ females with no genomic disturbance to produce the $\mathrm{F} 1$

537 generation. Embryos from F1 generation were genotyped as stated above and remaining embryos were

538 raised to adulthood. F1 offspring were screened again at $\sim 2$ months of age and, since mutation

539 transmission occurred in two males only per group, these Ht males were crossed with Wt females to

540 produce the F2 generation. Following the same genotyping strategy, F2 Ht males were crossed with Ht

541 females to produce the F3 generation. Finally, F3 homozygous (Hm; vtg1-/- and vtg3-/-) males and Hm

542 females with both alleles carrying the desired mutation were crossed to produce the F4 vtg mutants.

543

\section{$544 \quad$ 4.5. Tissue sampling and analyses}


546 were excised within 2-3 $\mathrm{h}$ after egg collection at the end of phenotyping experiment and after the fish

547 were euthanized with a lethal dose of 2-phenoxyethanol $(0.5 \mathrm{ml} / \mathrm{L})$. Ovary samples were aliquoted into

548 four pieces and stored according to subsequent analytical procedures; snap frozen for RNA and protein

549 extraction or placed in Bouin's solution for histological analyses. Liver samples were aliquoted in two

550 pieces and snap frozen until being used for LC-MS/MS or Western blotting.

\subsection{Quantitative real time PCR}

553 Total RNA was extracted from frozen liver using TriReagent (SIGMA) and cDNA was

554 synthesized using SuperScript III reverse transcriptase (Invitrogen, USA) from $1 \mu \mathrm{g}$ of total RNA

555 according to the manufacturer's instructions. Relative expression levels for all zebrafish vtgs (vtgl, 2, 3,

$5564,5,6$ and 7) in vtgl-KO female liver were measured using TaqMan real-time quantitative PCR (RT-

557 qPCR) using gene specific primers and dual-labeled probes (FAM, 6-carboxyfluorescein and a BHQ-1,

558 Black Hole Quencher 1 on 5' and 3' terminus, respectively). Sequences of these primers and probes used

559 in this experiment are given in S1 Table. Each qPCR was performed in $10 \mu 1$ reactions containing cDNA

560 (diluted at 1:25), $600 \mathrm{nM}$ of each primer, $400 \mathrm{nM}$ of hybrolysis probe and $1 \times$ TaqMan Fast Advanced

561 Master Mix (Applied Biosystems) according the manufacturer's instructions on a StepOnePlus real time

562 PCR instrument (Applied Biosystems). PCR cycling conditions were as follows: $95^{\circ} \mathrm{C}$ for 20 seconds, 40

563 cycles at $95^{\circ} \mathrm{C}$ for 1 second followed by an annealing-extension at $60^{\circ} \mathrm{C}$ for 20 seconds. The relative

564 abundance of the target cDNA within a sample set was calculated from a serial dilution curve made from

565 the cDNA pool, using StepOne software (Applied Biosystems). The $2^{-\Delta \Delta C T}$ mean relative quantification of

566 gene expression method with zebrafish $18 S$ as a reference gene was employed in this study. Relative

567 expression levels of all zebrafish vtgs in $v \operatorname{tg} 3-\mathrm{KO}$ female liver were measured using SYBR GREEN

568 qPCR Master Mix (SYBR Green Master Mix kit; Applied Biosystems) as indicated by the manufacturer

569 in a total volume of $10 \mu \mathrm{l}$, containing RT products diluted at 1:1000 and $400 \mathrm{nM}$ of each primer in order

570 to obtain PCR efficiency between 95 and $100 \%$. Sequences of primers used in this experiment are given 
571 in S1 Table. The RT-qPCR cycling protocol included 3 min initial denaturation at $95{ }^{\circ} \mathrm{C}$ followed by 40

572 cycles of $95{ }^{\circ} \mathrm{C}$ for $3 \mathrm{sec}$ and $60{ }^{\circ} \mathrm{C}$ for $30 \mathrm{sec}$ on a StepOnePlus thermocycler (Applied Biosystem). The

573 relative abundance of target cDNA within a sample set was calculated from a serially diluted cDNA pool

574 (standard curve) using Applied Biosystem StepOne V.2.0 software. Similarly, the $2^{-\Delta \Delta C T}$ mean relative

575 quantification of gene expression method with the mean expression value of zebrafish elongation factor

576 1a (eifla), ribosomal protein 13a $(r p l 13 a)$ and $18 S$ as reference were employed in this study. Primer

577 sequences and properties for these genes are also given in S1 Table. Obtained data was subjected to

578 independent samples Kruskal-Wallis nonparametric test $(\mathrm{p}<0.05)$ followed by Benjamini Hochberg

579 correction for multiple tests $(\mathrm{p}<0.1)$ (IBM SPSS Statistics Version 19.0.0, Armonk, NY).

\subsection{Western Blotting}

Samples of zebrafish liver, ovary and eggs were homogenized in $100 \mu 1$ of protein binding buffer containing 1mM AEBSF, 10mM Leupeptin, 1mM EDTA and $0.5 \mathrm{mM}$ DTT as indicated by Hiramatsu et

584 al. (2002) using a procellys tissue homogenizer (Bertin Instruments, France). Protein extracts were

585 separated from homogenates with centrifugation at $13000 \mathrm{rpm}+4{ }^{\circ} \mathrm{C}$ for 30 minutes to generate supernatant samples for SDS-PAGE. Protein concentrations of the samples were estimated by Bradford 587 Assay (Bradford, 1976) (Bio-Rad, Marnes-la-Coquette, France) and they were diluted to $4 \mu \mathrm{g}$ protein $\mu \mathrm{l}^{-1}$ 588 in ultrapure water, mixed 1:1 v/v with Laemmli sample buffer (Laemmli, 1970) containing 2589 mercaptoethanol, and boiled for $5 \mathrm{~min}$ before electrophoresis. A total of $10 \mu \mathrm{g}$ of sample protein was 590 loaded onto a precast 4-15\% acrylamide gradient Tris-HCl Ready Gel® (BioRad, Hercules, CA) with 4

$591 \%$ acrylamide stacking gel and electrophoresed at $150 \mathrm{~V}$ for $45 \mathrm{~min}$ using a Tris-glycine buffer system

592 (Laemmli, 1970). Biotinylated protein molecular weight markers (Vector Laboratories, USA) were used 593 to estimate the mass of separated proteins.

594 Proteins in the gels were transferred to PVDF membranes using a Trans-Blot ${ }^{\circledR}$ Turbo ${ }^{\text {TM }}$ Transfer

595 Starter System (BioRad) at $25 \mathrm{~mA}$ for $15 \mathrm{~min}$. Blots were blocked for $2 \mathrm{~h}$ with Casein solution in tris

596 buffered saline $(10 \mathrm{mM}$ Tris $\mathrm{HCl}$ containing $15 \mathrm{mM} \mathrm{NaCl})$ and $0.05 \%$ Tween 20 (TBST) to reduce non- 
597 specific reactions. Affinity purified polyclonal primary antibody raised against a specific peptide epitope 598 on lipovitellin light chain of zebrafish Vtg3 (anti-zfLvL3, GeneScript Custom Antibody production 599 Service, USA) was employed to detect Vtg3 or its product yolk proteins in liver, ovary and eggs from F3 600 vtg3-KO zebrafish. For this purpose, blots were incubated for $2 \mathrm{~h}$ at room temperature with the anti601 zfLvL3 at a 1:000 dilution in phosphate buffered saline $\left(10 \mathrm{mM} \mathrm{Na} 2 \mathrm{HPO}_{4}, \mathrm{pH} 7.5,150 \mathrm{mM} \mathrm{NaCl}\right)$.

602 Membranes were washed three times for 5 minutes in TBST solution and incubated in biotinylated goat 603 anti-rabbit IgG affinity purified secondary antibody diluted 1:8000 in casein solution for 30 minutes at 604 room temperature. Membranes were washed in TBST solution three times for 5 min each and incubated 605 in VECTASTAIN ${ }^{\circledR}$ ABC-AmP ${ }^{\mathrm{TM}}$ reagent (VECTASTAIN ABC-AmP Kit, for Rabbit IgG, 606 Chemiluminescent Western Blot Detection, Vector Laboratories) for 10 minutes at room temperature.

607 Following three washes of 5 minutes in TBST, membranes were equilibrated in $0.1 \mathrm{M}$ Tris buffer, $\mathrm{pH} 9.5$

608 before development in DuoLuX ${ }^{\mathrm{TM}}$ Substrate (Vector Laboratories) and exposure to chemiluminescent 609 signal detection on FUSION-FX7 advanced chemiluminescence/fluorescence system (Vilber Lourmat, 610 Germany).

\section{4.8. Liquid Chromatography Tandem Mass Spectrometry}

613 Protein extraction of liver and egg samples from $v \operatorname{tg} 1-\mathrm{KO}, v \operatorname{tg} 3-\mathrm{KO}$ and Wt female zebrafish 614 were done as described by Yilmaz et al. (2017). Briefly, samples were subjected to sonication in $20 \mathrm{mM}$, $615 \mathrm{pH} 7.4$, HEPES buffer on ice, soluble protein extracts were recovered following centrifugation $(15000 \mathrm{x}$ $616 \mathrm{~g})$ at $+4{ }^{\circ} \mathrm{C}$ for $30 \mathrm{~min}$ and the remaining pellet was re-sonicated in $30 \mathrm{mM}$ Tris $/ 8 \mathrm{M} \mathrm{Urea} / 4 \%$ CHAPS 617 buffer on ice. Ultracentrifugation $(105,000 \mathrm{xg})$ of the pooled protein extracts for $1 \mathrm{~h}$ at $4{ }^{\circ} \mathrm{C}$ was followed 618 by supernatant recovery and determination of the protein concentration by Bradford Assay (Bradford, 619 1976) (Bio-Rad, Marnes-la-Coquette, France). Samples of extracts were mixed with sample buffer and 620 DTT and denatured at $70{ }^{\circ} \mathrm{C}$ for $10 \mathrm{~min}$ before being subjected to SDS-PAGE (60 $\mu \mathrm{g}$ protein/sample 621 lane). When protein samples had completely penetrated the stacking gel ( $\sim 2$ minutes at $200 \mathrm{~V}-400 \mathrm{~mA}$ $622(\sim 23 \mathrm{~W}))$, electropohoresis was stopped and gels were briefly rinsed in MilliQ ultrapure water (Millipore 
623 S.A.S., Alsace, France) and then incubated in fixation solution containing $30 \% \mathrm{EtOH} / 10 \%$ acetic acid /

$62460 \%$ MilliQ water for $15 \mathrm{~min}$ in order to fix proteins on the gel. Gels were then washed in MilliQ water

625 three times for $5 \mathrm{~min}$ each and incubated in EZBlue ${ }^{\mathrm{TM}}$ Gel Staining Reagent (Sigma-Aldrich, Saint-

626 Quentin Fallavier, France) at room temperature with slight agitation for $2 \mathrm{~h}$, and de-stained in MilliQ

627 water at room temperature overnight. Subsequently, protein bands were excised from the gel and the

628 excised gel pieces were processed for tryptic digestion and peptide extraction as indicated by Yilmaz et

629 al. (2017). Once peptide extraction was completed, pellets containing digested peptides were resolubilized

630 in $30 \mu \mathrm{l}$ of $95 \% \mathrm{H}_{2} \mathrm{O}: 5 \%$ formic acid by vortex mixing for $10 \mathrm{~min}$ and diluted 10 times before being

631 subjected to LC-MS/MS.

632 Peptide mixtures were analyzed using a nanoflow high-performance liquid chromatography

633 (HPLC) system (LC Packings Ultimate 3000, Thermo Fisher Scientific, Courtaboeuf, France) connected

634 to a hybrid LTQ-OrbiTrap XL spectrometer (Thermo Fisher Scientific) equipped with a nanoelectrospray

635 ion source (New Objective), as previously described (Lavigne et al., 2012; Yilmaz et al., 2017). The

636 spectra search, protein identification, quantification by spectral counts, and spectral count normalization

637 were conducted as described by Yilmaz et al. (2017). To detect significant differences between group

638 mean N-SC values (vtgl-KO vs Wt or vtg3-KO vs $\mathrm{Wt}$ ) for different zebrafish Vtgs from liver and eggs,

639 an independent samples Kruskal-Wallis nonparametric test $(\mathrm{p}<0.05)$ followed by Benjamini Hochberg

640 correction for multiple tests $(\mathrm{p}<0.1)$ was used (IBM SPSS Statistics Version 19.0.0, Armonk, NY).

\section{4.9. Ethical Statement}

643 All experiments complied with French \& European regulations ensuring 'animal welfare' and that

644 'Animals will be held in the INRA UR1037 LPGP fish facility (DDCSPP approval \# B35-238-6).'

645 Experimental protocols involving animals were approved by the Comité Rennais d'éthique pour 646 l'expérimentation animale (CREEA). 


\section{COMPETING INTERESTS}

650 Authors declare no competing interests.

\section{6. FUNDING}

654 This study was supported by the Region Bretagne in France (SAD-2013)-FishEgg (8210); Project 655 \#13009218), the EC-Marie Skłodowska-Curie Actions within the frame of the IEF program (FP7656 PEOPLE-2013-IEF; FISHEGG: Project \# 626272) and Maternal Legacy (ANR-13-BSV7-0015).

\section{ACKNOWLEDGMENTS}

Authors would like to thank Dr. Amaury Herpin and Dr. Amine Bouchareb for their advices in

661 development of methodological strategies, and Dr. Craig V. Sullivan for their valuable contribution in 662 reviewing and evaluating the manuscript.

\section{REFERENCES}

666 Alix, M., Zarski, D., Chardard, D., Fontaine, P., Schaerlinger, B. (2017). Deformities in newly hatched 667 embryos of Eurasian perch populations originating from two different rearing systems. Journal of 668 Zoology, 302,126-137.

669 Altschul, S.F., Gish, W., Miller, W., Myers, E.W., Lipman, D.J. (1990). Basic local alignment search 670 tool. Journal of Molecular Biology, 215, 403-410.

671 Andersen, Ø., Xu, C., Timmerhaus, G., Kirste, K.H., Naeve, I., Mommens, M., Tveiten, H. (2017).

672 Resolving the complexity of vitellogenins and their receptors in the tetraploid Atlantic salmon (Salmo 673 salar): ancient origin of the phosvitin-less $\mathrm{VtgC}$ in chondrichthyean fishes. Molecular Reproduction 674 and Development, 84(11), 1191-1202. 
675 Babin, P.J., Carnevali, O., Lubzens, E., Schneider, W.J. (2007). Molecular aspects of oocyte 676 vitellogenesis in fish. In: Babin, P.J., Cerdà, J., Lubzens, E. (Eds.), The Fish Oocyte: From Basic 677 Studies to Biotechnological Applications. Springer, Dordrecht, pp. 39-76.

678 Babin, P.J. (2008). Conservation of a vitellogenin gene cluster in oviparous vertebrates and identification 679 of its traces in the platypus genome. Gene, $413,76-82$.

680 Bhattacharya, D., Sarkar, S., Juim, S.K., Nath, P. (2018). Induction of fertilizable eggs by conspecific 681 vitellogenin implantation in captive female walking catfish, Clarias batrachus. Aquaculture Research, $682 \quad 49,3167-3175$.

683 Bradford, M.M. (1976). A rapid and sensitive method for the quantitation of microgram quantities of 684 protein utilizing the principle of protein-dye binding. Analytical Biochemistry, 72, 248-254.

685 Carnevali, O., Centonze, F., Brooks, S., Marota, I., Sumpter, J.P. (1999a) Molecular cloning and 686 expression of ovarian cathepsin D in seabream, Sparus aurata. Biology of Reproduction, 66, 785-791.

687 Carnevali, O., Carletta, R., Cambi, A., Vita, A., Bromage, N. (1999b). Yolk formation and degradation 688 during oocyte maturation in seabream, Sparus aurata: involvement of two lysosomal proteinases. 689 Biology of Reproduction, 60, 140-146.

690 Carnevali, O., Cionna, C., Tosti, L., Lubzens, E., Maradonna, F. (2006). Role of cathepsins in ovarian 691 follicle growth and maturation. General and Comparative Endocrinology, 146, 195-203.

692 Cerdà, J., Fabra, M., Raldúa, D. (2007). Physiological and molecular basis of fish oocyte hydration. In: 693 Babin, P.J., Cerdà, J., Lubzens, E. (Eds.), The Fish Oocyte: From Basic Studies to Biotechnological 694 Applications. Springer, Dordrecht, pp. 349-396.

695 Cerdà, J., Zapater, C., Chauvigné, F., Finn, R.N. (2013). Water homeostasis in the fish oocyte: new 696 insights into the role and molecular regulation of a teleost-specific aquaporin. Fish Physiology and 697 Biochemistry, 39, 19-27.

698 Costa, R.S., de Souza, F.M.S., Senhorini, J.A., Veríssimo-Silveira, R., Ninhaus-Silveira, A. (2017). 699 Effects of cryoprotectants and low temperatures on hatching and abnormal embryo development of 700 Prochilodus lineatus (Characiformes: Prochilodontidae). Neotropical Ichthyology, 15, e170043. 
701 Doudna, J.A., Charpentier, E. (2014). The new frontier of genome engineering with CRISPR-Cas9.

$702 \quad$ Science 346, 6213; DOI: 10.1126/science.1258096.

703 Ellis, T.R., Crawford, B.D. (2016). Experimental dissection of metalloproteinase inhibition-mediated and

704 toxic effects of phenanthroline on zebrafish development. International Journal of Molecular $705 \quad$ Sciences, 17, 1503 DOI:10.3390/ijms17091503.

706 Finn, R.N. (2007). The maturational disassembly and differential proteolysis of paralogous vitellogenins

707 in a marine pelagophil teleost: A conserved mechanism of oocyte hydration. Biology of Reproduction, $708 \quad 76,936-948$.

709 Finn, R.N., Kristoffersen, B.A. (2007). Vertebrate vitellogenin gene duplication in relation to the "3R 710 hypothesis": correlation to the pelagic egg and the oceanic radiation of teleosts. PLoS One, 2(1):e169.

711 Finn, R.N., Kolarevic, J., Kongshaug, H., Nilsen, F. (2009). Evolution and differential expression of a 712 vertebrate vitellogenin gene cluster. BMC Evolutionary Biology, 9:2.

713 Finn, R.N., Fyhn, H.J. (2010). Requirement for amino acids in ontogeny of fish. Aquaculture Research, $714 \quad 41,684-716$.

715 Flouriot, G., Pakdel, F., Valotaire, Y. (1996). Transcriptional and post-transcriptional regulation of 716 rainbow trout estrogen receptor and vitellogenin gene expression. Molecular and Cellular 717 Endocrinology, 124, 173-183.

718 Gabor, K.A., Goody, M.F., Mowel, W.K., Breitbach, M.E., Gratacap, R.L. Witten, P.E., Kim, C.H. 719 (2014). Influenza A virus infection in zebrafish recapitulates mammalian infection and sensitivity to 720 anti-influenza drug treatment. Disease Models and Mechanisms, 7, 1227-1237.

721 Hanke, N., Staggs, L., Schroder, P., Litteral, J., Fleig, S., Kaufeld, J., Pauli, C., Haller, H., Schiffer, M. 722 (2013). "Zebrafishing" for Novel Genes Relevant to the Glomerular Filtration Barrier. BioMed 723 Research International, 658270; http://dx.doi.org/10.1155/2013/658270.

724 Hiramatsu, N., Hara, A., Hiramatsu, K., Fukada, H., Webe,r G.M., Denslow, N.D., Sullivan, C.V. (2002).

725 Vitellogenin-derived yolk proteins of white perch, Morone americana: Purification, characterization, 726 and vitellogenin-receptor binding. Biology of Reproduction, 67, 655-667. 
727 Hiramatsu, N., Cheek, A.O., Sullivan, C.V., Matsubara, T., Hara, A. (2005). Vitellogenesis and endocrine 728 disruption. In: Mommsen, T.P., Moon, T. (Eds.), Biochemistry and Molecular Biology of Fishes, 729 Environmental Toxicology Vol. 6. 2005; Elsevier Science Press, Amsterdam, The Netherlands, pp. $730 \quad 431-471$ (Chapter 16, $562 \mathrm{pp})$.

731 Hiramatsu, N., Todo, T., Sullivan, C.V., Schilling, J., Reading, B., Matsubara, T., Ryu, Y-W., Mizuta, H.,

732 Luo, W., Nishimiya, O., Wu, M., Mushirobira, Y., Yilmaz, O., Hara, A. (2015). Ovarian yolk

733 formation in fishes: molecular mechanisms underlying formation of lipid droplets and vitellogenin-

734 derived yolk proteins. General and Comparative Endocrinology, 221, 9-15.

735 Juin, S.K., Mukhopadhyay, B.C., Biswas, S.R., Nath, P. (2017). Conspecific vitellogenin induces the

736 expression of vg gene in the Indian male walking catfish, Clarias batrachus (Linn.). Aquaculture 737 Reports, 6, 61-67.

738 Kimmel, C.B., Ballard, W.W., Kimmel, S.R., Ullmann, B., Schilling, T. (1995). Stages of embryonic 739 development of the zebrafish. Developmental Dynamics, 203, 253-310.

740 Krøvel, A.V., Olsen, L.C. (2002). Expression of a vas::EGFP transgene in primordial germ cells of the 741 zebrafish. Mechanisms of Development, 116, 141-150.

742 Laemmli, U.K. (1970). Cleavage of structural proteins during the assembly of the head of bacteriophage

743 T4. Nature, 227, 680-685.

744 Lavigne, R., Becker, E., Liu, Y., Evrard, B., Lardenois, A., Primig, M., Pineau, C. (2012). Direct iterative 745 protein profiling (DIPP)-an innovative method for large-scale protein detection applied to budding 746 yeast mitosis. Molecular and Cellular Proteomics, 11, M111-012682.

747 Levi, L., Pekarski, I., Gutman, E., Fortina, P., Hyslop, T., Biran, J., Levavi-Sivan, B., Lubzens, E. (2009).

748 Revealing genes associated with vitellogenesis in the liver of the zebrafish (Danio rerio) by 749 transcriptome profiling. BMC Genomics, 10:141. http://dx. doi.org/10.1186/1471-2164-10-141.

750 Levi, L., Ziv, T., Admon, A., Levavi-Sivan, B., Lubzens, E. (2012). Insight into molecular pathways of 751 retinal metabolism, associated with vitellogenesis in zebrafish. American Journal of Physiology752 Endocrinology and Metabolism, 302, E626-E644. 
753 Li, A., Sadasivam, M., Ding, J.L. (2003). Receptor-ligand interaction between vitellogenin receptor

754 (VtgR) and vitellogenin (Vtg), implications on low density lipoprotein receptor and apolipoprotein

$755 \mathrm{~B} / \mathrm{E}$. The first three ligand binding repeats of VtgR interact with the amino-terminal region of Vtg. The

756 Journal of Biological Chemistry, 278, 2799-2806.

757 Liu, H., Sui, T., Liu, D., Liu, T., Chen, M., Deng, J., Xu, Y., Li, Z. (2018). Multiple homologous genes 758 knockout (KO) by CRISPR/Cas9 system in rabbit. Gene, 647, 261-267.

759 Lubzens, E., Bobe, J., Young, G., Sullivan, C.V. (2017). Maternal investment in fish oocytes and eggs:

760 The molecular cargo and its contributions to fertility and early development. Aquaculture, 472, 107-

$761 \quad 143$.

762 Marschang, P., Brich, J., Weeber, E.J., Sweatt, J.D., Shelton, J.M., Richardson, J.A., Hammer, R.E., Herz,

763 J. (2004). Normal development and fertility of knockout mice lacking the tumor suppressor gene

764 LRP1b suggests functional compensation by LRP1. Molecular and Cellular Biology, 24,3782-3793.

765 Matsubara, T., Koya, Y. (1997). Course of proteolytic cleavage in three classes of yolk proteins during

766 oocyte maturation in barfin flounder, Verasper moseri, a marine teleost spawning pelagic eggs.

767 Journal of Experimental Zoology, 278, 189-200.

768 Matsubara, T., Ohkubo, N., Andoh, T., Sullivan, C.V., Hara, A. (1999). Two forms of vitellogenin,

769 yielding two distinct lipovitellins, play different roles during oocyte maturation and early development

770 of barfin flounder, Verasper moseri, a marine teleost spawning pelagic eggs. Developmental Biology,

$771213,18-32$.

772 Matsubara, T., Nagae, M., Ohkubo, N., Andoh, T., Sawaguchi, S., Hiramatsu, N., Sullivan, C.V., Hara, A.

773 (2003). Multiple vitellogenins and their unique roles in marine teleosts. Fish Physiology and 774 Biochemistry, 28, 295-29.

775 Nelson, E.R., Habibi, H.R. (2013). Estrogen receptor function and regulation in fish and other vertebrates.

776 General and Comparative Endocrinology, 192, 15-24. http://dx.doi.org/10.1016/j. ygcen.2013.03.032. 
777 Opresko, L.K., Wiley, H.S. (1987). Receptor-mediated endocytosis in Xenopus oocytes: I-

778 Characterization of vitellogenin receptor system. The Journal of Biological Chemistry, 262, 4109-

$779 \quad 4115$.

780 Ottesen, O.H., Bolla, S. (1998). Combined effects of temperature and salinity on development and 781 survival of Atlantic halibut larvae. Aquaculture International, 6, 103-120.

782 Patiño, R., Sullivan, C.V. (2002). Ovarian follicle growth, maturation and ovulation in teleost fish. Fish 783 Physiology and Biochemistry, 26, 57-70.

784 Prykhozhij, S.V., Rajan, V., Gaston, D., Berman, J.N. (2015). CRISPR MultiTargeter: A web tool to find 785 common and unique CRISPR single guide RNA targets in a set of similar sequences. PLoS ONE, 786 10(3): e0119372. doi:10.1371/journal.pone.0119372.

787 Reading, B.J., Hiramatsu, N., Sawaguchi, S., Matsubara, T., Hara, A., Lively, M.O., Sullivan, C.V.

788 (2009). Conserved and variant molecular and functional features of multiple vitellogenins in white 789 perch (Morone americana) and other teleosts. Marine Biotechnology, 11, 169-187.

790 Reading, B.J., Sullivan, C.V. (2011). The Reproductive Organs and Processes - Vitellogenesis in Fishes,

791 Editor: Anthony P. Farrell, Encyclopedia of Fish Physiology, Academic Press, pp 635-646, 792 https://doi.org/10.1016/B978-0-12-374553-8.00257-4.

793 Reading, B.J., Sullivan, C.V., Schilling, J. (2017). Vitellogenesis in fishes. Reference Module in Life

794 Sciences, Elsevier, https://doi.org/10.1016/B978-0-12-809633-8.03076-4.

795 Reis-Henriques, M.A., Cruz, M.M., Periera, J.O. (1997). The modulating effect of vitellogenin on the 796 synthesis of $17 \mathrm{~b}$-estradiol by rainbow trout (Oncorhynchus mykiss) ovary. Fish Physiology and 797 Biochemistry, 16, 181-186.

798 Reis-Henriques, M.A., Ferriera, M., Silva, L., Dias, A. (2000). Evidence for an involvement of 799 vitellogenin in the steroidogenic activity of rainbow trout (Oncorhynchus mykiss) vitellogenic oocytes. 800 General and Comparative Endocrinology, 117, 260-267. 
801 Reith, M., Munholland, J., Kelly, J., Finn, R.N., Fyhn, H.J. (2001). Lipovitellins derived from two forms

802 of vitellogenin are differentially processed during oocyte maturation in haddock (Melanogrammus 803 aeglefinus). Journal of Experimental Zoology, 291, 58-67.

804 Ren, L., Lewis, S.K., Lech, J.J. (1996). Effects of estrogen and nonylphenol on the post-transcriptional 805 regulation of vitellogenin gene expression. Chemico-Biological Interactions, 100, 67-76.

806 Ribas, L., Piferrer, F. (2013). The zebrafish (Danio rerio) as a model organism, with emphasis on 807 applications for finfish aquaculture research. Reviews in Aquaculture, 5, 1-32.

808 Sander, J.D., Zaback, P.Z., Joung, J.K., Voytas, D.F., Dobbs, D. (2007). Zinc Finger Targeter (ZiFiT): an 809 engineered zinc finger/target site design tool. Nucleic Acids Research, 35, W599-605.

810 Sander, J.D., Maeder, M.L., Reyon, D., Voytas, D.F., Joung, J.K., Dobbs, D. (2010). ZiFiT (Zinc Finger

811 Targeter): an updated zinc finger engineering tool. Nucleic Acids Research, 38, W462-468.

812 Sawaguchi, S., Ohkubo, N., Koya, Y., Matsubara, T. (2005). Incorporation and utilization of multiple

813 forms of vitellogenin and their derivative yolk proteins during vitellogenesis and embryonic 814 development in the mosquitofish, Gambusia affinis. Zoological Sciences, 22, 701-710.

815 Sawaguchi, S., Ohkubo, N., Matsubara, T. (2006a). Identification of two forms of vitellogenin-derived 816 phosvitin and elucidation of their fate and roles during oocyte maturation in the barfin flounder, 817 Verasper moseri. Zoological Sciences, 23, 1021-1029.

818 Sawaguchi, S., Kagawa, H., Ohkubo, N., Hiramatsu, N., Sullivan, C.V., Matsubara, T. (2006b).

819 Molecular characterization of three forms of vitellogenin and their yolk protein products during oocyte 820 growth and maturation in red seabream (Pagrus major), a marine teleost spawning pelagic eggs. 821 Molecular Reproduction and Development, 73, 719-736.

822 Sievers, F., Wilm, A., Dineen, D.G., Gibson, T.J., Karplus, K., Li, W., Lopez, R., McWilliam, H., 823 Remmert, M., Söding, J., Thompson, J.D., Higgins, D. (2011). Fast, scalable generation of high 824 quality protein multiple sequence alignments using Clustal Omega. Molecular Systems Biology, 7, 5825 39. doi: $10.1038 / \mathrm{msb} .2011 .75$. 
826 Sullivan, C.V., Yilmaz, O. (2018). Vitellogenesis and yolk proteins, fish. Editor: Michael K. Skinner,

827 Encyclopedia of Reproduction (Second Edition), Academic Press, pp 266-277, 828 https://doi.org/10.1016/B978-0-12-809633-8.20567-0.

829 Sun, B., Pankhurst, N.W. (2006). In vitro effect of vitellogenin on steroid production by ovarian follicles 830 of greenback flounder, Rhombosolea tapirina. Comparative Biochemistry and Physiology Part A, 144, $831 \quad 75-85$

832 Sztal, T.E., McKaige, E.A., Williams, C., Ruparelia, A.A., Bryson-Richardson, R.J. (2018). Genetic 833 compensation triggered by actin mutation prevents the muscle damage caused by loss of actin protein. $834 \quad$ PLoS Genetics, 14: e1007212.

835 Thorsen, A., Fyhn, H.J. (1996). Final oocyte maturation in vivo and in vitro in marine fishes with pelagic 836 eggs; yolk protein hydrolysis and free amino acid content. Journal of Fish Biology, 48, 1195-1209.

837 Trubiroha, A., Gillotay, P., Giusti, N., Gacquer, D., Libert, F., Lefort, A., Haerlingen, B., De Deken, X., 838 Opitz, R., Costagliola, S. (2018). A Rapid CRISPR/Cas-based Mutagenesis Assay in Zebrafish for 839 Identification of Genes Involved in Thyroid Morphogenesis and Function. Scientific Reports, 8, 5647 840 https://doi.org/10.1038/s41598-018-24036-4.

841 Tsuruwaka, Y., Konishi, M., Shimada, E. (2015). Loss of wwox expression in zebrafish embryos causes 842 edema and alters Ca2+ dynamics. PeerJ, 3: e727; DOI 10.7717/peerj.727.

843 Xie, S-L., Bian, W-P., Wang, C., Junaid, M., Zou, J-X., Pei, D-S. (2016). A novel technique based on in 844 vitro oocyte injection to improve CRISPR/Cas9 gene editing in zebrafish. Scientific Reports, 6, 34555; 845 doi: $10.1038 / \operatorname{srep} 34555(2016)$.

846 Yang, J., Li, Z., Gan, X., Zhai, G., Gao, J., Xiong, C., Qiu, X., Wang, X., Yin, Z., Zheng, F. (2016). 847 Deletion of Pr130 Interrupts Cardiac Development in Zebrafish. International Journal of Molecular $848 \quad$ Sciences, 17: 1746; doi:10.3390/ijms17111746.

849 Yilmaz, O., Prat, F., Ibáñez, J.A., Koksoy, S., Amano, H., Sullivan, C.V. (2016). Multiple vitellogenins 850 and product yolk proteins in European sea bass (Dicentrarchus labrax): Molecular characterization, 
853 Yilmaz, O., Patinote, A., Nguyen, T., Com, E., Lavigne, R., Pineau, C., Sullivan, C.V., Bobe, J. (2017).

854 Scrambled eggs: Proteomic portraits and novel biomarkers of egg quality in zebrafish (Danio rerio).

855 PLoS ONE, 12: e0188084. https://doi.org/10.1371/journal.pone.0188084.

856 Yilmaz, O., Patinote, A., Nguyen, T., Bobe, J. (2018). Multiple vitellogenins in zebrafish (Danio rerio):

857 quantitative inventory of genes, transcripts and proteins, and relation to egg quality. Fish Physiology

858 and Biochemistry, https://doi.org/10.1007/s10695-018-0524-y (Epub ahead of print).

859 Zhang, X., Lin, Q., Ren, F., Zhang, J., Dawar, F.U., Mei, J. (2018). The dysregulated autophagy signaling

860 is partially responsible for defective podocyte development in wtla mutant zebrafish. Aquaculture and

$861 \quad$ Fisheries, 3, 99-105.

\section{FIGURE LEGENDS}

Fig 1. Schematic representation of the general strategy for CRISPR target design in the zebrafish

$867 v t$ knock out (KO) study. A) Type-I vtg knock out (vtg1-KO). vtgl is depicted as representative of the

868 five targeted type-I zebrafish $v \operatorname{tg}$ genes. B) Type-III $v \operatorname{tg}$ knock out ( $v \operatorname{tg} 3-\mathrm{KO})$. Target sites are shown by

869 brown colored arrows labeled as sg followed by 1,2 or 3 indicating the targeted zebrafish vtg type and the

870 number of the target site (i.e. $\operatorname{sg} 11, \mathrm{sg} 12$, and sg13: single guide RNAs (sgRNAs) for target sites 1, 2, and

8713 for $v \operatorname{tg} 1$, respectively. $\operatorname{sg} 31, \operatorname{sg} 32$, and $\operatorname{sg} 33$ : $\operatorname{sgRNAs}$ for target sites 1,2 , and 3 for $v \operatorname{tg} 3$, respectively).

872 Arrows are oriented to indicate the sense/antisense orientation of each target. Numbers above each target

873 site specify its exact location by nucleotide in the genomic sequence of the zebrafish vtgs. Primers used in

874 screening for introduced mutations by PCR are shown as yellow arrowheads outlined in green, which are

875 oriented to indicate the sense/antisense orientation of the primer. Numbers below each primer site indicate

876 its exact position by nucleotide in the genomic sequence of the targeted gene (see also S1 Fig). Horizontal 
877 brackets below indicate areas screened for mutations by PCR using selected primer combinations; bold

878 green text below the brackets indicates the primer pair followed by the size of the band (bp) expected for 879 wild type gDNA in agarose gel electrophoresis (see Fig 3). 11Fw, vtg1 target1 forward primer; 12Rv, $880 v \operatorname{tg} 1$ target2 reverse primer; $13 \mathrm{Rv}, v \operatorname{tg} 1$ target 3 reverse primer; $12 \mathrm{Fw}, v \operatorname{tg} 1$ target2 forward primer; $31 \mathrm{Fw}$, $881 v \operatorname{tg} 3$ target1 forward primer; $32 \mathrm{Rv}, v \operatorname{tg} 3$ target2 reverse primer; $33 \mathrm{Rv}, v \operatorname{tg} 3$ target 3 reverse primer; $32 \mathrm{Fw}$, $882 v t g 3$ target2 forward primer. Primer sequences are given in S1 Table.

883

884 Fig 2. Location of mutations introduced by CRISPR/Cas9 in the predicted polypeptide sequence of

885 targeted zebrafish vtgs. The yolk protein domain structures of Vtg1 (representative of zebrafish type-I

886 Vtgs) and Vtg3 are pictured in 5' $>$ 3' orientation above each panel. Light gray horizontal bars represent

887 the lipovitellin heavy and light chain $(\mathrm{LvH}, \mathrm{LvL})$ and phosvitin $(\mathrm{Pv})$ domains of the respective $\mathrm{Vtg}(\mathrm{Vtg} 3$

888 lacks a Pv domain) and are labeled above in large bold type. Sequences within these bars indicate the N-

889 terminus of each yolk protein domain, the starting points of which are also indicated by vertical bars in

890 the polypeptide sequence shown below. The 85-residue Vtg receptor-binding domain (RbD) and the

891 critical 8-residue Vtg receptor-binding motif $(\underline{\boldsymbol{R} \boldsymbol{b} M})$ located within this domain, which were identified by

$892 \mathrm{Li}$ et al. (2003) in the $\mathrm{LvH}$ domain of blue tilapia (Orechromis aureus) VtgAb, are shown in the

893 polypeptide sequences in boldface italic type, with the $\boldsymbol{R} \boldsymbol{b} \boldsymbol{M}$ sequence being additionally underlined and

894 also shown in the yolk protein domain map above. Residues encoded by nucleotide sequences targeted by

895 sgRNAs for Cas9 editing are framed in magenta-shaded boxes. Cas9 created mutations (large deletions)

896 are indicated with dashes replacing amino acid (aa) residues and the size of deletions in aa (234 aa and

897239 aa for $v \operatorname{tg} 1-\mathrm{KO}$ and $v \operatorname{tg} 3-\mathrm{KO}$, respectively) in these regions are labeled by gray shaded text. Short

898 sequences that were employed as epitopes to develop Vtg domain-specific antibodies against Vtg1-LvH

899 (anti-LvH1) and $\mathrm{Vtg} 3-\mathrm{LvL}$ (anti-LvL3) are indicated by framed text on the LvH and LvL domains of

$900 \mathrm{Vtg} 1$ and $\mathrm{Vtg} 3$, respectively, with their location also highlighted by black arrows labeled with the epitope

901 names given by vertically-oriented text in the panel margins. 
903 Fig 3. Detection of CRISPR/Cas9-introduced mutations by embryo genotyping and production of

904 F4 generation vtg-KO mutants. Left and middle panels illustrate genotyping of embryos at $24 \mathrm{~h}$ post-

905 fertilization (hpf) by PCR for $v \operatorname{tgl} 1-\mathrm{KO}$ (representative of zebrafish type-I vtgs) and vtg3-KO lines,

906 respectively, from the F0 to F4 generation. F0 indicates the generation reared from microinjected embryos

907 and F1-4 represent offspring raised from each subsequent generation. The agarose gel electrophoresis

908 results shown here represent screening of 10 randomly sampled embryos as representatives of their

909 generations and two additional wild type embryos as controls. Bands comprised of wild type intact gDNA

910 (3642 bp and $1733 \mathrm{bp}$ for $v \operatorname{tg} 1$ and $v \operatorname{tg} 3$, respectively) and mutated gDNA (2361 bp and $551 \mathrm{bp}$ for $v \operatorname{tg} 1$ -

$911 \mathrm{KO}$ and $v \operatorname{tg} 3-\mathrm{KO}$, respectively) are shown and highlighted by black arrowheads on the right side of each

912 panel. Open circles; non-related wild type fish (Wt) carrying intact $(v \operatorname{tg} 1+/+$ or $v \operatorname{tg} 3+/+)$ genomic DNA.

913 Open diamonds; sibling wild type individuals, which do not carry the desired mutation in either allele

$914(v \operatorname{tg} 1+/+$ or $v \operatorname{tg} 3+/+)$ of their gDNA. Open triangles; heterozygous $(\mathrm{Ht})$ individuals carrying the

915 introduced mutation on only a single allele (vtg1-/+ or vtg3-/+) in their genomic DNA. Asterisks;

916 homozygous embryos $(\mathrm{Hm})$ carrying the introduced mutation in both alleles (vtg1-/- or vtg3-/-) of their

917 genomic DNA. The panel on the far right illustrates the general strategy followed to establish pure

918 zebrafish lines bearing the desired Cas9 introduced mutation. This process involved stepwise reproductive

919 crosses (indicated by X) between males ( $)$ ) and females ( + ) indicated here with zebrafish icons. F0-4

920 represents the zebrafish generations produced in the process. Images of sub-adult fish are shown for

921 simplicity at generation F4; all or most of these fish were actually inviable and did not survive past early

922 developmental stages (see text for details).

924 Fig 4. Relative quantification of vtg gene expression in vtg-KO zebrafish female liver. A)

925 Comparison of gene expression levels for all vtgs in F3 vtgl-KO female liver (Hm, homozygous; Ht,

926 heterozygous; wt, sibling wild type) versus non-related wild type female liver (Wt). TaqMan qPCR-2 ${ }^{-\Delta \Delta C T}$

927 mean relative quantification of gene expression was employed using zebrafish 18S ribosomal RNA (18S) 
928 as the reference gene. Data were statistically analyzed using a Kruskal Wallis nonparametric test $\mathrm{p}<0.05$

929 followed by Bejamini Hochberg corrections for multiple tests $\mathrm{p}<0.1$. B) Comparison of gene expression

930 levels for all vtgs in F3 vtg3-KO female liver (Hm, Ht and wt) versus Wt female liver. SYBR Green

931 qPCR-2 ${ }^{-\Delta \Delta C T}$ mean_relative quantification of gene expression normalized to the geometric mean

932 expression of zebrafish elongation factor 1a (eifla), ribosomal protein L13a (rpll3a) and $18 S$ was

933 employed. Data were statistically analyzed using a Kruskal Wallis nonparametric test $\mathrm{p}<0.05$ followed by

934 Benjamini Hochberg corrections for multiple tests $\mathrm{p}<0.1$. In the box plots, the centerlines indicate the

935 median for each data set, upper boxes indicate the difference of the $3^{\text {rd }}$ quartile from the median, lower

936 boxes indicate the difference of the $1^{\text {st }}$ quartile from the median. Top whiskers indicate difference of the

937 maximum value from the $3^{\text {rd }}$ quartile and the bottom whiskers indicate the difference of the minimum

938 values from the $1^{\text {st }}$ quartile in each data set. In both panels, numbers below $\mathrm{x}$-axis labels indicate sample

939 size and lowercase letters above the error bars represent significant differences between means $(\mathrm{p}<0.05)$.

940 For box plots sharing a common letter superscript, the means are not significantly different.

941

942 Fig 5. Relative quantification of multiple vitellogenins by LC-MS/MS in vtg-KO zebrafish female

943 liver and eggs. A) Comparisons of mean normalized spectral counts (N-SC) for Vtg protein levels in Wt

944 versus Hm F3 vtgl-KO female zebrafish livers and in eggs obtained from these females, indicated by dark

945 and light gray vertical bars, respectively. Vertical brackets indicate SEM. B) Corresponding comparison

946 of N-SC for Vtg protein levels in Wt versus F3 Hm vtg3-KO female zebrafish livers and in eggs obtained

947 from these females. Asterisks indicate statistically significant differences between group means detected

948 by an independent samples Kruskal Wallis non-parametric test $(\mathrm{p}<0.05)$ followed by Benjamini Hochberg

949 correction for multiple tests $(\mathrm{p}<0.1)$

951 Fig 6. Detection of $\mathrm{Vtg3}$ in vtg3-KO versus wild type female liver, ovary and eggs by Western

952 blotting. An affinity-purified, polyclonal anti-zfLvL3 antibody was employed to detect LvL3 in this

953 experiment. Numbers on the left of each panel indicate the mass of molecular weight marker proteins 
954 (kDa). M, marker protein ladder; Hm, homozygous; Ht, heterozygous; Wt, non-related wild type. Bands

955 that were detected in Ht and Wt zebrafish whose mass corresponds to that of zebrafish Vtg3 LvL (LvL3,

$956 \sim 24 \mathrm{kDa}$ ) are indicated with brackets and labels immediately underneath (LvL3).

957 Fig 7. Phenotypic measurements of F3 vtg-KO females and their F4 progeny. Bar graphs indicate

958 mean values $( \pm$ SEM) for measurements of each parameter and labels below the x-axes indicate the groups

959 that were compared. In the panel at the bottom right, mean hatching percentages for $\mathrm{Hm} v \operatorname{tg} 1-\mathrm{KO}, \mathrm{Hm}$

$960 v \operatorname{vg} 3-\mathrm{KO}$, and Wt eggs are shown as circles, triangles and diamonds, respectively. Numbers on the $\mathrm{x}$-axis

961 accompanied by dashed- and solid-lined arrows represent sampling times in hours or days post spawning,

962 respectively. In all graphs, asterisks and black stars indicate mean values that are statistically significantly

963 different from corresponding Wt mean values based upon results of an independent samples t-test

$964(\mathrm{p}<0.01)$ followed by Benjamini Hochberg corrections for multiple tests in the case of hatching

965 percentage $(\mathrm{p}<0.05)$.

Fig 8. Comparisons of survival percentages for homozygous F4 vtg1-KO and vtg3-KO zebrafish

embryos and larvae versus wild type offspring. Line plots represent mean survival percentages and

969 numbers on the $\mathrm{x}$-axis accompanied by dashed- and solid-lined arrows represent sampling times in hours

970 or days post spawning during the observation period. Mean survival percentages for $\mathrm{Hm} v \operatorname{tg} 1-\mathrm{KO}, \mathrm{Hm}$

971 vtg3-KO and unrelated Wt embryos and larvae at each time point are indicated by circles, triangles and

972 diamonds, respectively, and vertical lines indicate SEM. Asterisks and black stars indicate mean values

973 that are statistically significantly different from corresponding mean wild type (Wt) values based upon

974 results of an independent samples t-test $(\mathrm{p}<0.01)$ followed by Benjamini Hochberg corrections for

975 multiple tests $(\mathrm{p}<0.05)$.

977 Fig 9. Observed phenotypes of F4 vtg-KO offspring compared to wild type offspring. A) Hm vtg1-

978 KO unhatched embryos and hatched larvae at 4 dps. B) Wt larva at 4 dps. C) Hm vtg3-KO larvae at 4 dps.

979 D) Hm $v \operatorname{tg} 1$-KO larvae at 8 dps. E) Wt larva at 8 dps. F) Hm $v \operatorname{tg} 3-\mathrm{KO}$ larvae at 8 dps. Special features of 
981 indicate $1000 \mu \mathrm{m}$.

\section{SUPPORTING INFORMATION LEGENDS}

\section{S1 Fig. Location and character of mutations introduced by CRISPR/Cas9 in zebrafish vtgs A-B)}

986 Location on genomic DNA. Schematic representations of the intron/exon structure of zebrafish $v \operatorname{tg} 1$

987 (representative of type-I vtgs) and $v \operatorname{tg} 3$ are given at the top of panels $\mathbf{A}$ and $\mathbf{B}$, respectively. Horizontal

988 line segments indicate introns and filled gold boxes indicate exons. Exons bearing CRISPR/Cas9 target

989 sequences are indicated by magenta-colored arrows pointing upwards to the target name (sg11, sg12, and

$990 \mathrm{sg} 13$ for $v \operatorname{tg} 1$; sg31, sg32, and $\mathrm{sg} 33$ for $v \operatorname{tg} 3)$. Horizontal dashed lines bearing dual arrowheads indicate

991 regions where mutations were introduced, with the size of deletions in bp given below the arrows (1281

$992 \mathrm{bp}$ and $1182 \mathrm{bp}$ for $v \operatorname{tg} 1-\mathrm{KO}$ and $v \operatorname{tg} 3-\mathrm{KO}$, respectively). The lower sections of panels $\mathbf{A}$ and $\mathbf{B}$ show

993 Clustal Omega alignments for partial genomic sequences of the $v \operatorname{tg} 1$ and $v \operatorname{tg} 3$ genes, respectively,

994 covering regions where Cas9 introduced targeted mutations. Sequences of undisturbed wild type alleles

995 are labeled $v \operatorname{tg} 1+/+$ and $v \operatorname{tg} 3+/+$, and sequences of homozygous mutated alleles are labeled $v \operatorname{tg} 1-/-$ and

$996 v t g 3-/-$, respectively. Dashes were introduced to illustrate regions where deletions occurred in the vtg1-/-

997 and $v \operatorname{tg} 3-/-$-sequences. Nucleotide positions are indicated by numbers on the right and asterisks indicate

998 nucleotide identity. Target sequences are enclosed in magenta-colored boxes emphasized by magenta-

999 colored arrows on the right. Intron sequences are given in dark gray font enclosed in light gray filled

1000 frames and are labeled by Intron on the right with the same formatting. Exons are shown in regular black

1001 font and labeled on the right with exon numbers (e.g. Exon 6, 7, 8...). Exons bearing the target sites are

1002 also labeled with the target name below in parenthesis (e.g. Exon 14/(sg12)). C-D) Location on predicted

1003 cDNA. Nucleotide sequences targeted by sgRNAs for Cas9 editing and present in the predicted transcript

1004 are framed in magenta-shaded boxes. The deleted region of the transcript is indicated by dashes replacing

1005 nucleotide residues and the size of the deletion in bp is given by gray highlighted text in this region (703 
1006 bp deletion for $v t g 1$ and 714 bp deletion for $v \operatorname{tg} 3)$. The sequence encoding the receptor-binding domain

1007 (RbD) on the $\mathrm{LvH}$ of the respective Vtg is shown in italic bold typeface with the sequence encoding the 1008 critical, short receptor-binding motif $(\boldsymbol{R} \boldsymbol{b} \boldsymbol{M})$ being additionally underlined. E-F) Location on predicted

1009 polypeptide sequences. Schematic representations of the yolk protein domain structures of Vtg1 1010 (representative of zebrafish type-I Vtgs) and Vtg3 are given in 5'>3' orientation above each panel. Light 1011 gray horizontal bars represent the lipovitellin heavy and light chain (LvH, LvL) and the phosvitin (Pv)

1012 yolk protein domains of the respective Vtg (Vtg3 lacks a Pv domain) and are labeled above in large bold

1013 type. Sequences within these bars indicate the N-terminus of each yolk protein domain, the start of which

1014 is also indicated by vertical bars in the polypeptide sequence shown below. The $\boldsymbol{R} \boldsymbol{b} \boldsymbol{M}$ is shown in bold

1015 italic underlined font on the gray horizontal bars in the LvH1 and LvH3 domains. The $\boldsymbol{R} \boldsymbol{b} \boldsymbol{D}$ and $\boldsymbol{R} \boldsymbol{b} \boldsymbol{M}$ are

1016 also indicated in the polypeptide sequences shown below by bold italic font with the $\boldsymbol{R} \boldsymbol{b} \boldsymbol{M}$ being

1017 additionally underlined. Residues encoded by nucleotide sequences targeted by sgRNAs for Cas9 editing

1018 are framed in magenta-shaded boxes. Cas9 created mutations (large deletions) are indicated with dashes

1019 replacing amino acid (aa) residues and the size of deletions in aa (234 aa and 239 aa for vtgl-KO and

$1020 v \operatorname{vtg} 3-\mathrm{KO}$, respectively) in these regions are labeled by gray shaded text. Short sequences that were

1021 employed as epitopes to develop Vtg domain-specific antibodies against Vtg1-LvH (anti-zfLvH1) and

1022 Vtg3-LvL (anti-zfLvL3) are indicated by framed text on the LvH and LvL domains of Vtg1 and Vtg3,

1023 respectively, with their location also highlighted by black arrows labeled with the epitope names given by

1024 vertically-oriented text in the panel margins.

1026 S1 Table. Targets, primers and probes utilized in vtg1-KO and vtg3-Ko studies. Target oligo an 1027 screening primer names are given according Figure 1. CRISPR recognition NGG motifs are highlighted by bold 1028 typeface on sequences. Position of primers, target sites and probes on vitellogenin (Vtg) yolk protein (YP) 1029 domains are given on the far right columns. 


\section{A) vtg1-KO}

$v \operatorname{tg} 1,4,5,6 \& 7=6671-7493$ bp gDNA bioRxiv preprint trist posted online Oct. 29, 2018; doi: http://dx.doi.org/10.1101/456053. The copyright holder for this preprint

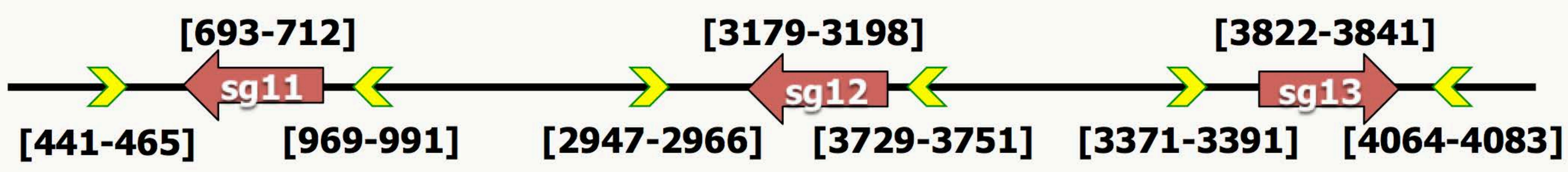

11Fw-12Rv: 3310bp

11Fw-13Rv: 3642bp

12Fw-13Rv: 1137bp

B) vtg3-KO

vtg3 = 20947 bp gDNA

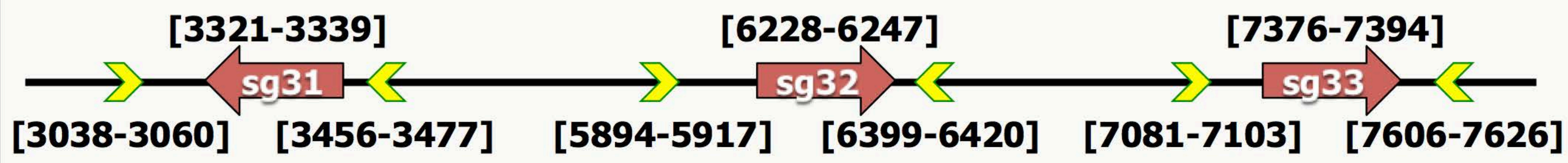

31Fw-32Rv: 3420bp

31Fw-33Rv: 4589bp

32Fw-33Rv: 1733bp 


\section{LvH1}

5 'QQFNLVP---IVTKSKDL------------------- REILDT-RMSKTAT->ENSDART00000050238 peptide: ENSDARP00000050237 pep:KNOWN_protein_coding MRAVVLALTVALVAC | QQFNLVPEFAHDKTYVYKYEALLLGGLPQEGLARAGIKVSSKVL ISATTENTYLMKLMDPLLYEYAGTWPKDPFVPATKLTSALAAQLQIPIKFEYANGVVGKV FAPAGVSPTVMNLHRGI LNILQLNLKKTQNIYEMQEAGAQGVCRTHYVINEDPKANHIIV TKSKDLSHCQERIMKDVGLAYTERCAECTERVKSLIETATYNY IMKPADNGALIAEATVE EVYQFSPFNE IHGAAMMEAKOTLAFVEIEKTPVVPIKADYMPRGSLQYEFATEILOTPIQ LMKISDAPAOIVEVLKHLVSNNKDMVHDDAPFKFVOLVOLLRVASLEKIEAIWSOFKDKP VYRRWLLDALPAVGTPVIIKFIKEKFLAGEFTTPEF IQTLVIALQMVTADPETIKMTASL ATHEKFATIPALREVVMLGYGSLIAKYCVAVPTCPAELLRPIHEIATEAISKNDIPEITL ALKVMGNAGHPSSLKPIMKLLPGLRTAANALPIRVOVDAI-_-_-_-_-_-_-_-_---

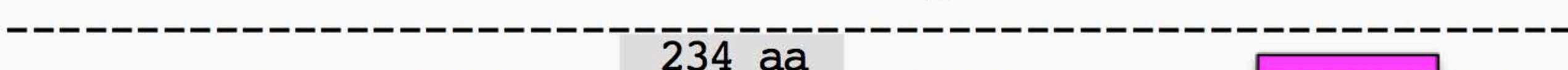
---------------------- deletion KPLLAAEVRRILPTAVGVPMEF SWYTAAVAAASVNVQATITPALPEKLESMTYEQLKKTD VQFQAEARPSVALQTFAVMGVNTAF IQAAVMARGKIRTIAPGKVAARADILKGNYKVEAI PVELPEHIASASFETYAVVRNIEDHSAERSVPLVPELSLQNSQASYAGDLSSEMSSVASV RAPAPFDRTLCYAVPYIEIKGCVEVHSHNAAF IRNSTLFYI IGHHSVRAAVARAEGPAVE RLEFEVQVGPRAAERLVKQINI IDDDTPEGQAFLLKL |REILDTEAKNAPVSSESSSSRN SRSSSSRSTSTSTSSSSSSSSSSSSSSSSSMSSS | RMSKTATI IEPFRKF HKDRYLAHHS ATKDTSSGSAAASFEQMQKQNRFLGNDIPPVFAI IARAVRADQKLLGYQLAAYFDKPTAR VQLIVSSIAENDNMKICADGALLSKHKVTGKF SWGAECKQYAVFAKAEAGVLGEFPAARL EVEWERLPIIVTTYAKKLGKHILTAAYDTGFRFERATNSEKEIELTAALPSQRSLNIIAR IPEITMSKRDIYLPVAVPINPDGTFSIETYEDFLAWIQKYIKEE

\section{LvH3}

LvL3

3'

5' MANYEPF--IVTRIVDIT TTQDLD--- 3'

>ENSDART00000014979 peptide: ENSDARP00000023158 pep:KNOWN_protein_coding RLCLCLLVALAASE | MANYEPFLNSKKTYEYKYEGLVQVGRELPHLVESALKLRCTFKII GESPHTFVLQVSNVDFEDFNGIPGKSVFSPSKNITKHLSAEISQP I IFEYSKGQITDIRT APGVSNTVVNIVRGILGFLQVTVKTTQSFYELIELGIHGLCQSSYTVDEDSNAKELIVTR IVDITNCQQPASLYRGMALAPEDKLSKQRGESVVSTVKHTYTVKSTADGGQITKAFAQER QYFSPFNVKGGNF-- -------

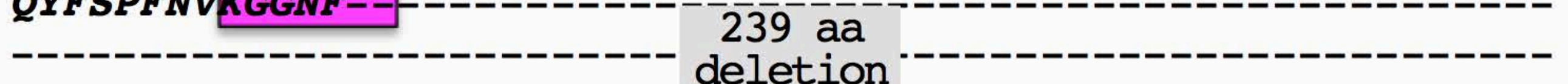

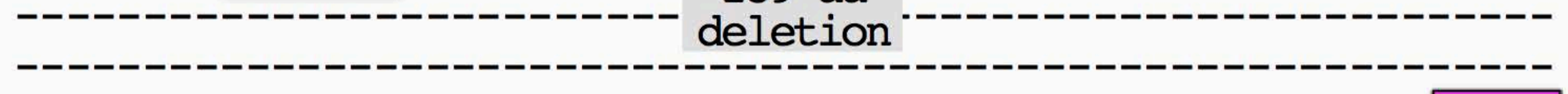

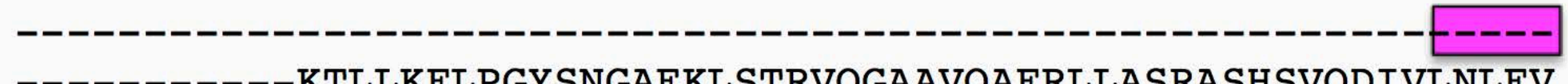
----------KTLLKFLPGYSNGAEKLSTRVQGAAVQAFRLLASRASHSVQDIVLNLFV QKHLPAEIRMLACIVLLETKPSTALISVVSEVLLEEADLQVASFSYSLLKGFAKSRTPDN QHLSIACNIAMKILTRKLGHLSYRYSKNLHFDWFHDDFLFGTSADVYMLQNESPIPTKLM LKGKF HF IGRILQF LEFGIRADGLKDLF AGKIPELTKDLGISDLASILKILSNWQSLPKD KPLLTAYARVFGQEAFLMDVSRDSVQS I IKSFSPSAGKESKVWERIQDVQKGTSWHWTKP HLVYEARF IQPTCLGLPVEISKYYSVVNAVTMKAKAEINPPPKEHLGELLSSDISMQTDG FIGVTKDHFLFHGINTDLFQCGTELKSKVSMGLPWAFDLKINPKEQTYEMNLTPSKSVTE LF SVSSNVYAVLRNIEDPTSSKITPMMPETGESWQGVPLRMLPPLRDEQTKKSGMKFRQC AEAKIYGTALCIEAEAKRAHYLHEYPLYYLLGDTHFSYSLEPAKDAKPIEKIQIQVSASR QHPSVMSGMVNLNQRVFKETRDENTSCEERKTSSSLPV | TQDLDVTPDPVVTVKALSLSP QAKPLGYEGVAFYLPTAOKDDIEMIVSEVGEEANWKMCANAHFDKTHTSAKAHLRWGAEC QTYDVSMRVSAACQPESKPSISTKINWGTLPSVFTTVGQIVQEYVPGVSYIMGFYQKKEE NPERQASVIVVASSPETFDLKVKIPERTIYKKKIPSPIELLGIEAANLTMST

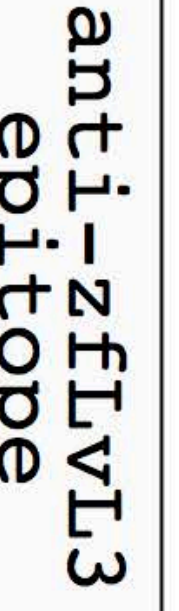




\section{vtg1-KO Embryo Genotyping}

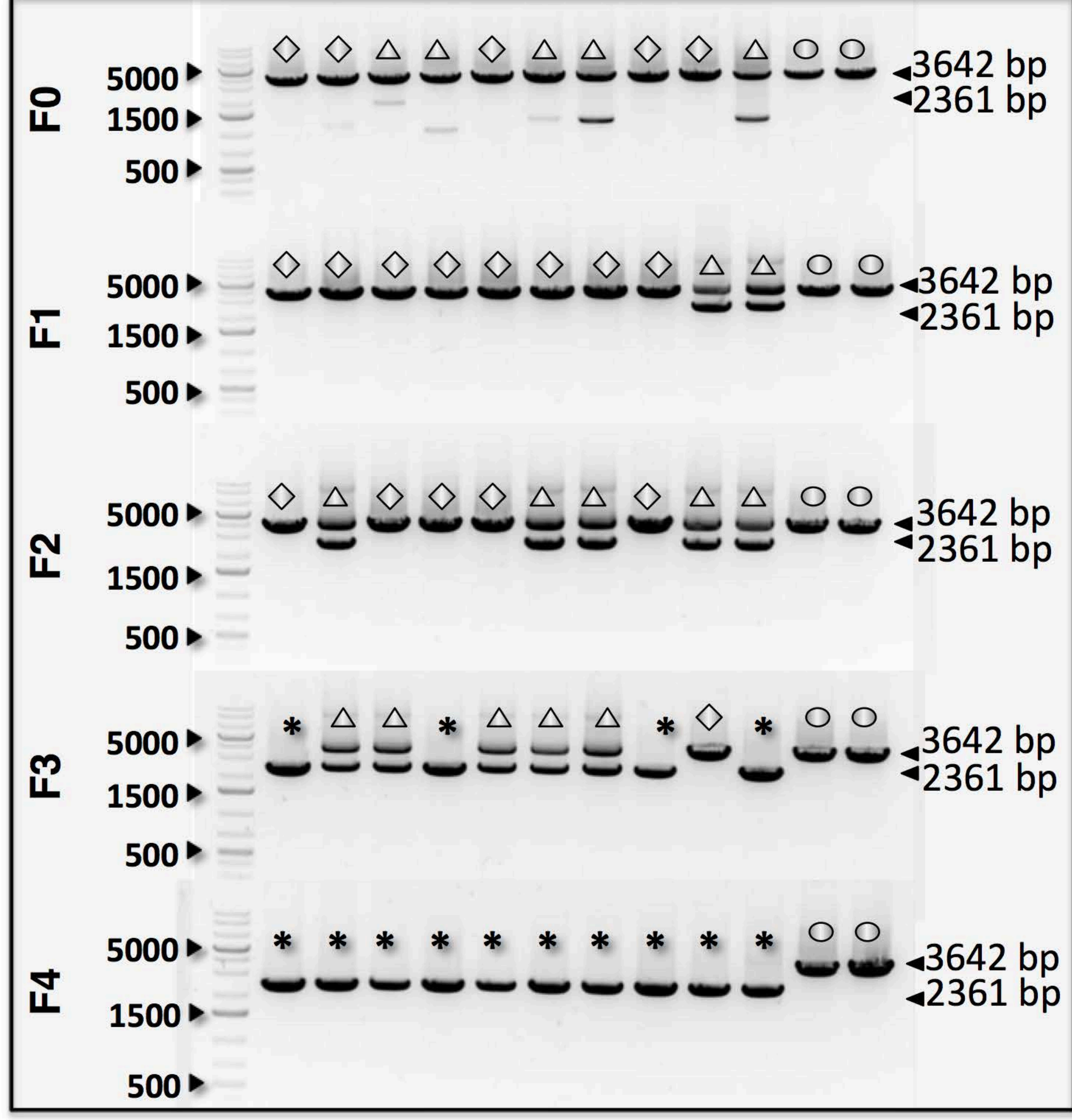

\section{vtg3-KO Embryo Genotyping}

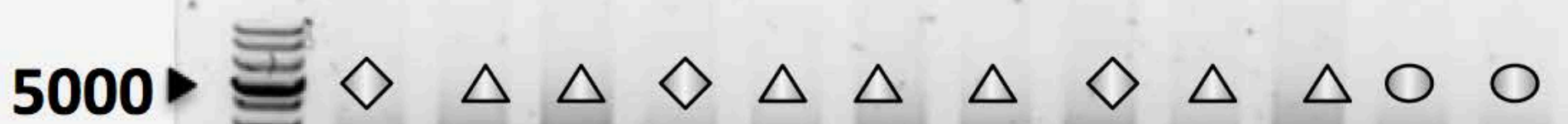

1500 • 500 $三 \quad-\quad---4551 \mathrm{bp}$

5000 $\equiv \Delta \diamond \diamond \diamond \Delta \diamond \diamond \diamond \diamond \Delta, 0$

1500 키-- - - - - - - - - 1733 bp 500 -

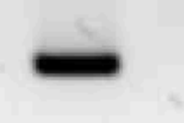

$5000 \triangleright \triangleq \diamond \Delta \Delta \diamond \diamond \diamond \Delta \Delta \diamond \Delta \Delta^{\prime} 00$

$1500 \triangleright \equiv-\quad--\infty---1733 \mathrm{bp}$

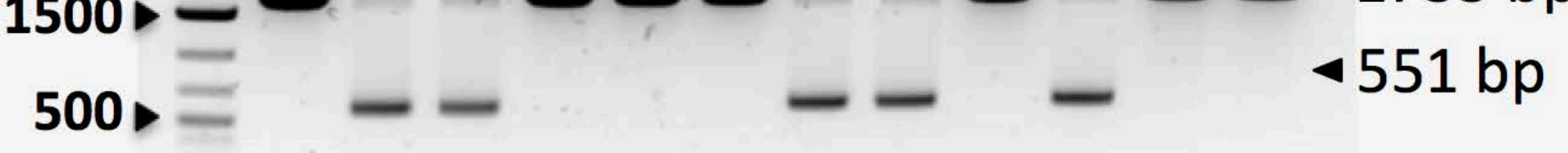

5000 $\doteq \diamond \Delta * * * \Delta \diamond \Delta * \Delta \circ 0$

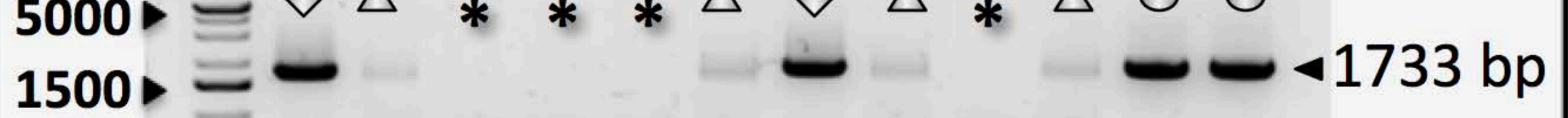
500 $\equiv-ー-ー-4551 b p$

00

1500 * $* * * * * * * * * * 1733 \mathrm{bp}$

\section{Pure Line Production}

$\stackrel{+}{1} \times \stackrel{0^{7}}{ }$

$\stackrel{0}{=}$.

$\mathrm{Wt} ; \mathrm{vtg}+/+$

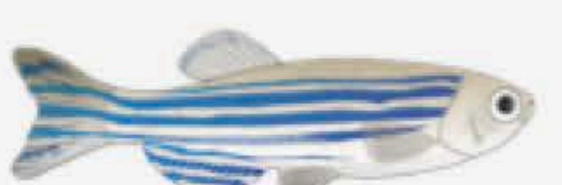

Wt; vtg +/+

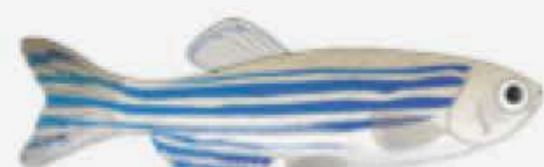

$\frac{}{\mathrm{Hm} ; v t g-/-}$

4551 bp
$\mathrm{Ht} ; \mathrm{vtg}-/+$

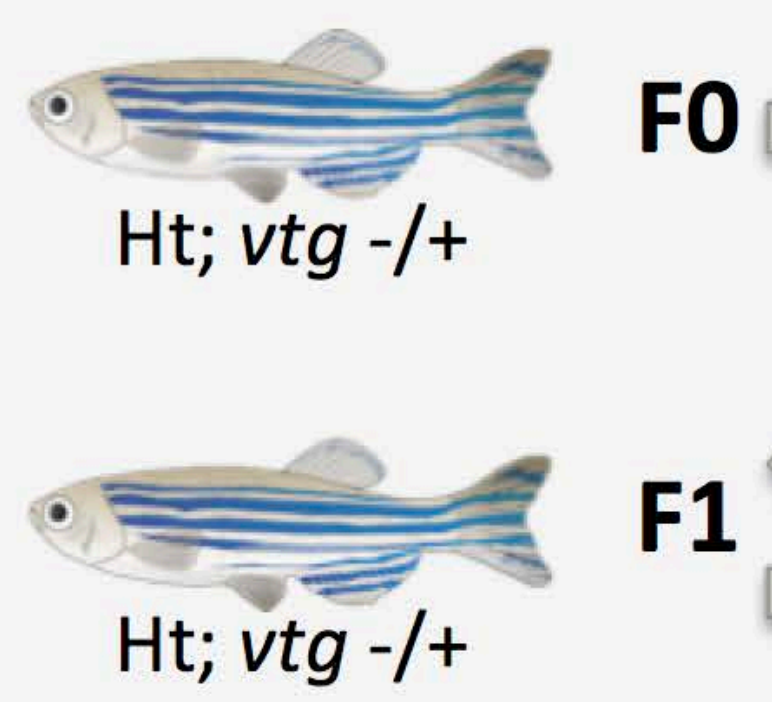

$\mathrm{Ht} ; \mathrm{vtg}-/+$

F2

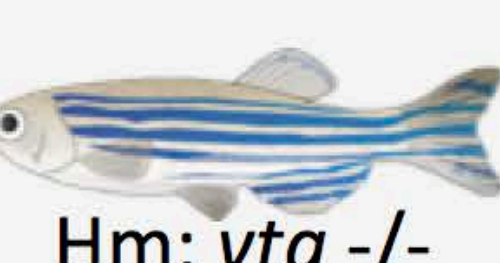

F3

(6) (6) (6) F4 


\section{A) vtg expression in vtg1-KO liver}
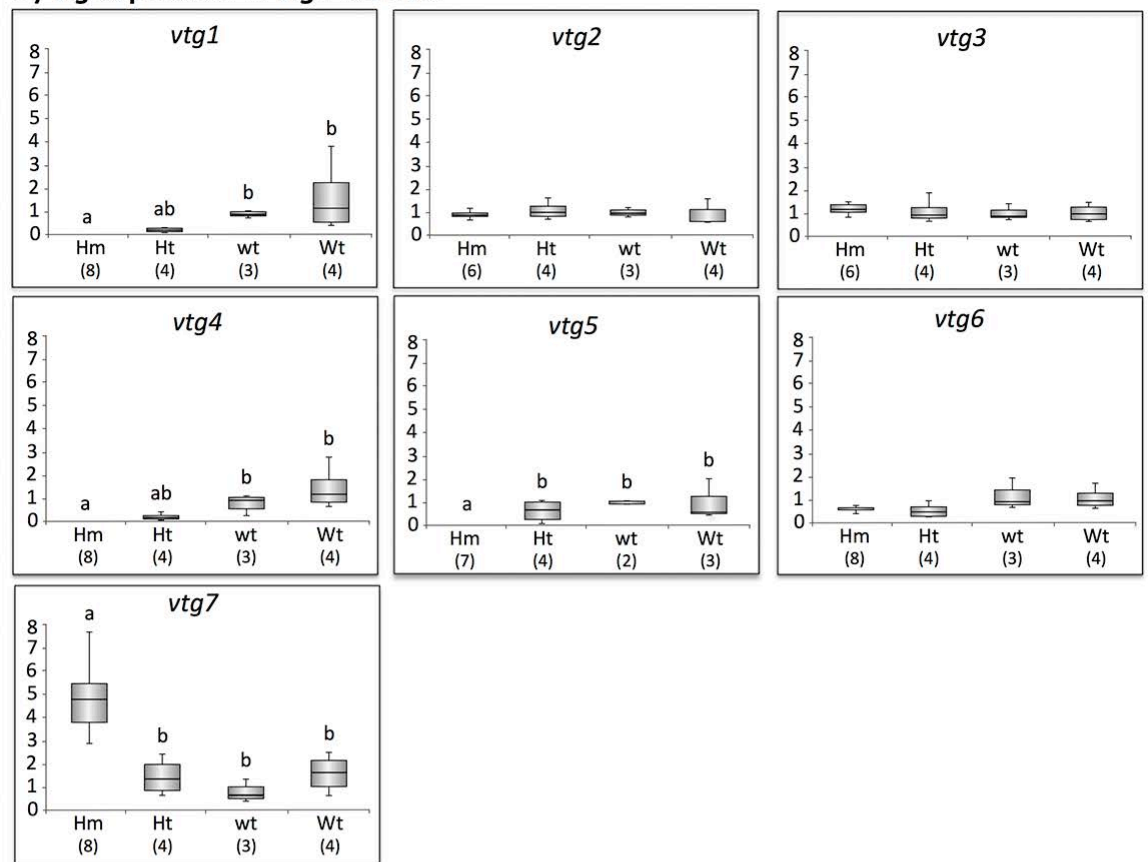

\section{B) vtg expression in vtg3-KO liver}
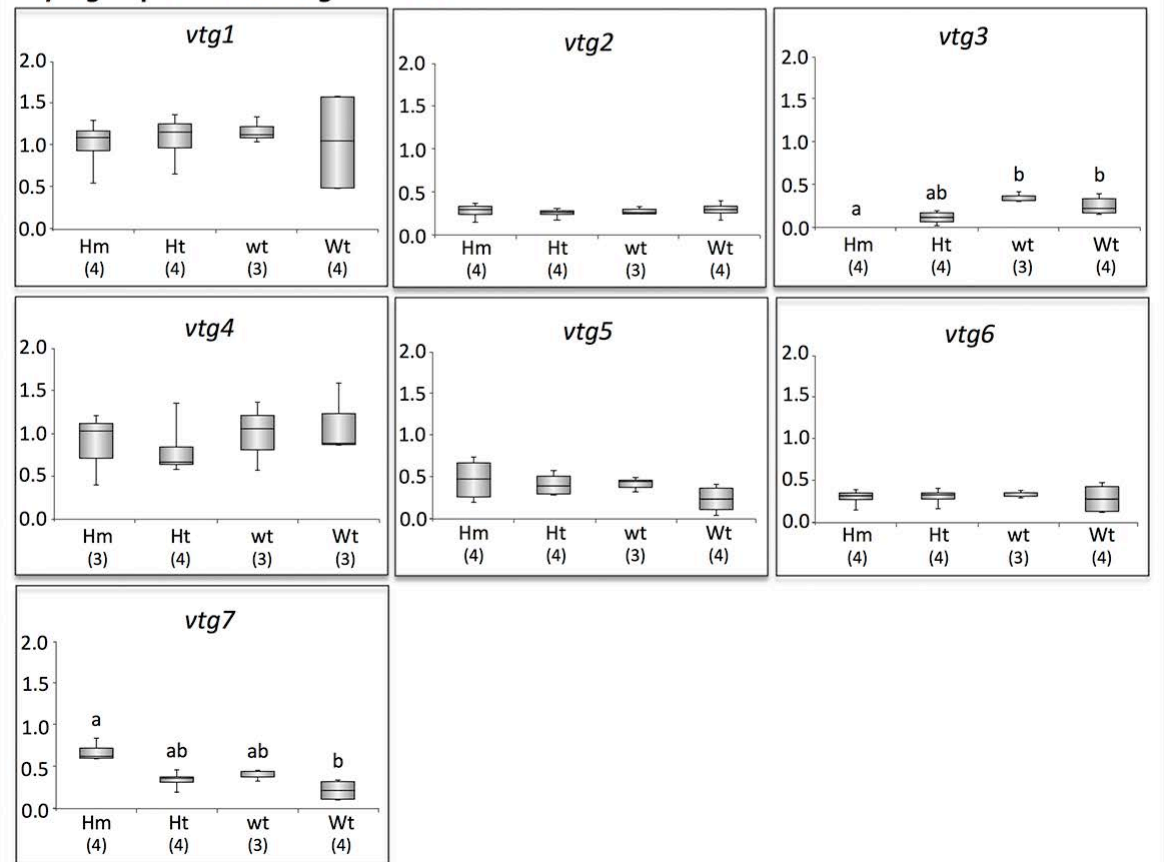


\section{A) vtg1-KO}

Liver

Eggs
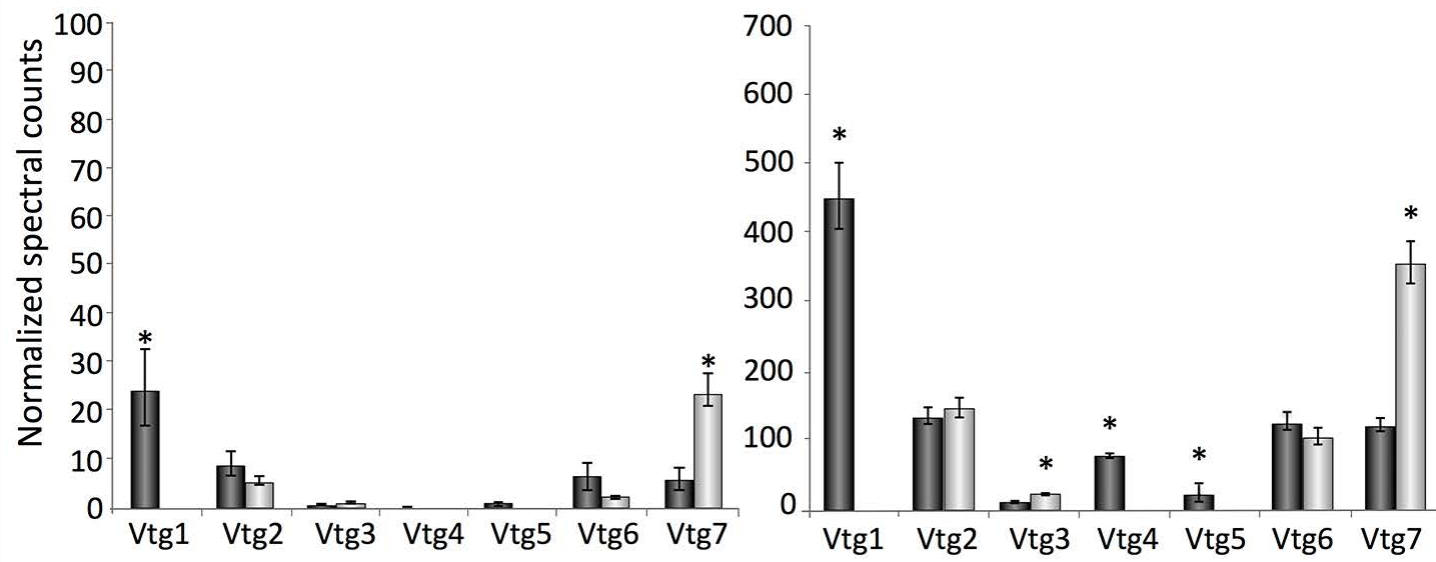

$\square \mathrm{Wt}(\mathrm{N}=4) \quad \square v \operatorname{tg} 1-\mathrm{KO}(\mathrm{N}=4)$

$\square \mathrm{Wt}(\mathrm{N}=4) \quad \square v t g 1-\mathrm{KO}(\mathrm{N}=4)$

\section{B) vtg3-KO}

Liver

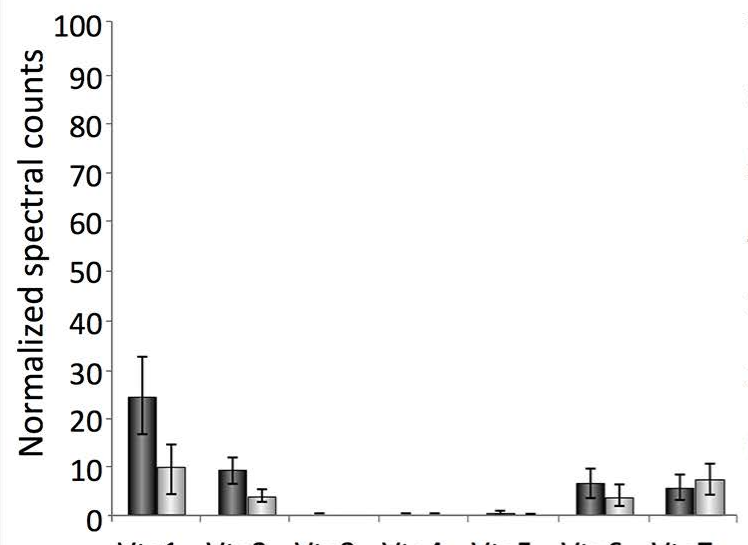

$\begin{array}{lllllll}\text { Vtg1 } & \text { Vtg2 } & \text { Vtg } & \text { Vtg } & \text { Vtg } 5 & \text { Vtg6 } & \text { Vtg7 }\end{array}$
Eggs

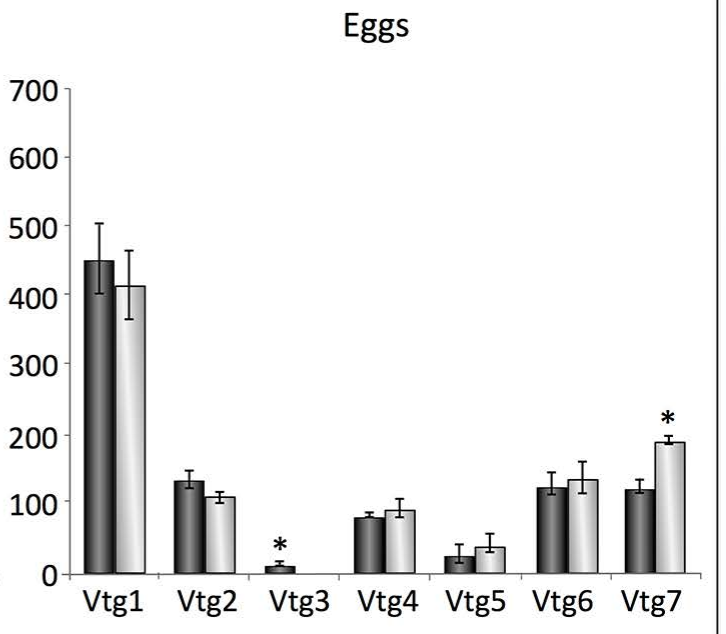

$\square \mathrm{Wt}(\mathrm{N}=4) \quad \square v \operatorname{tg} 3-\mathrm{KO}(\mathrm{N}=4)$ 


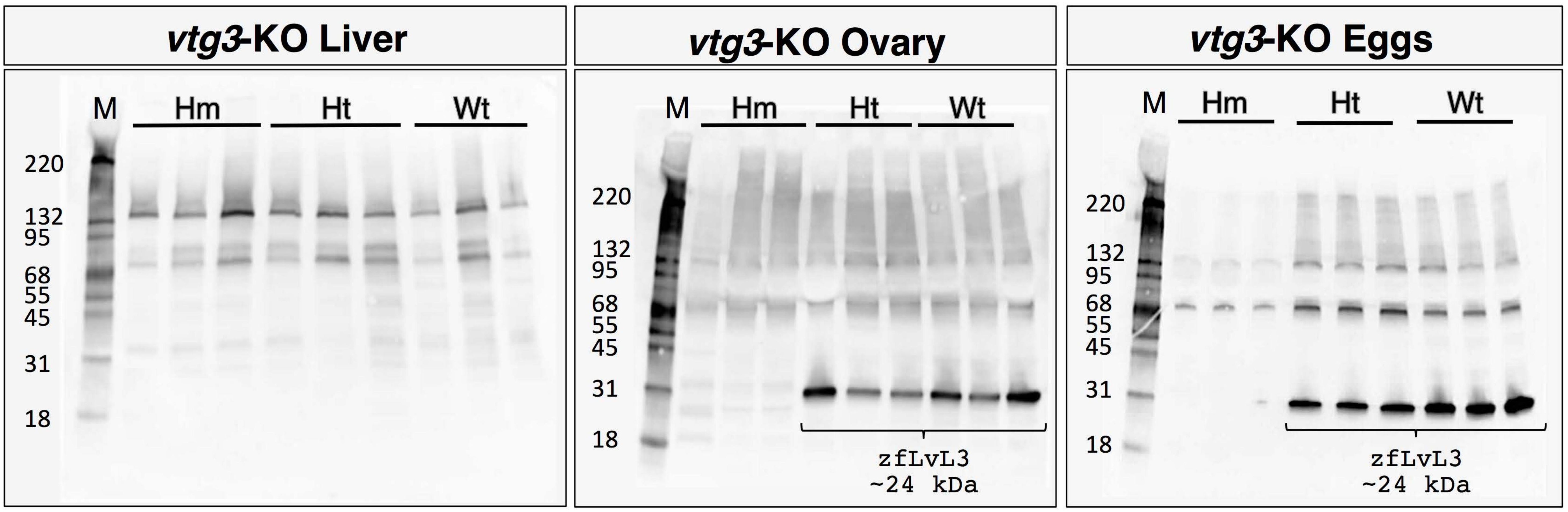




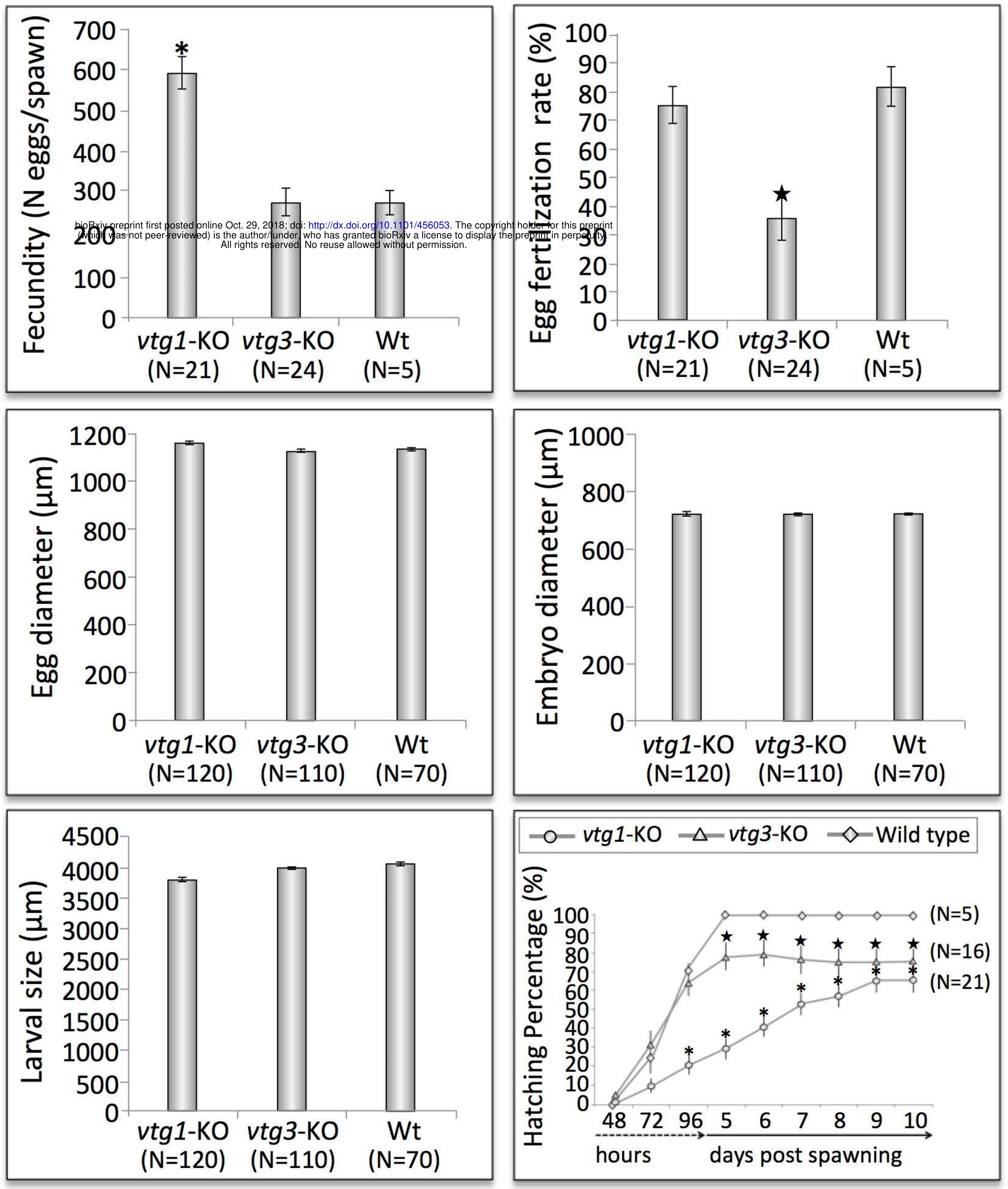



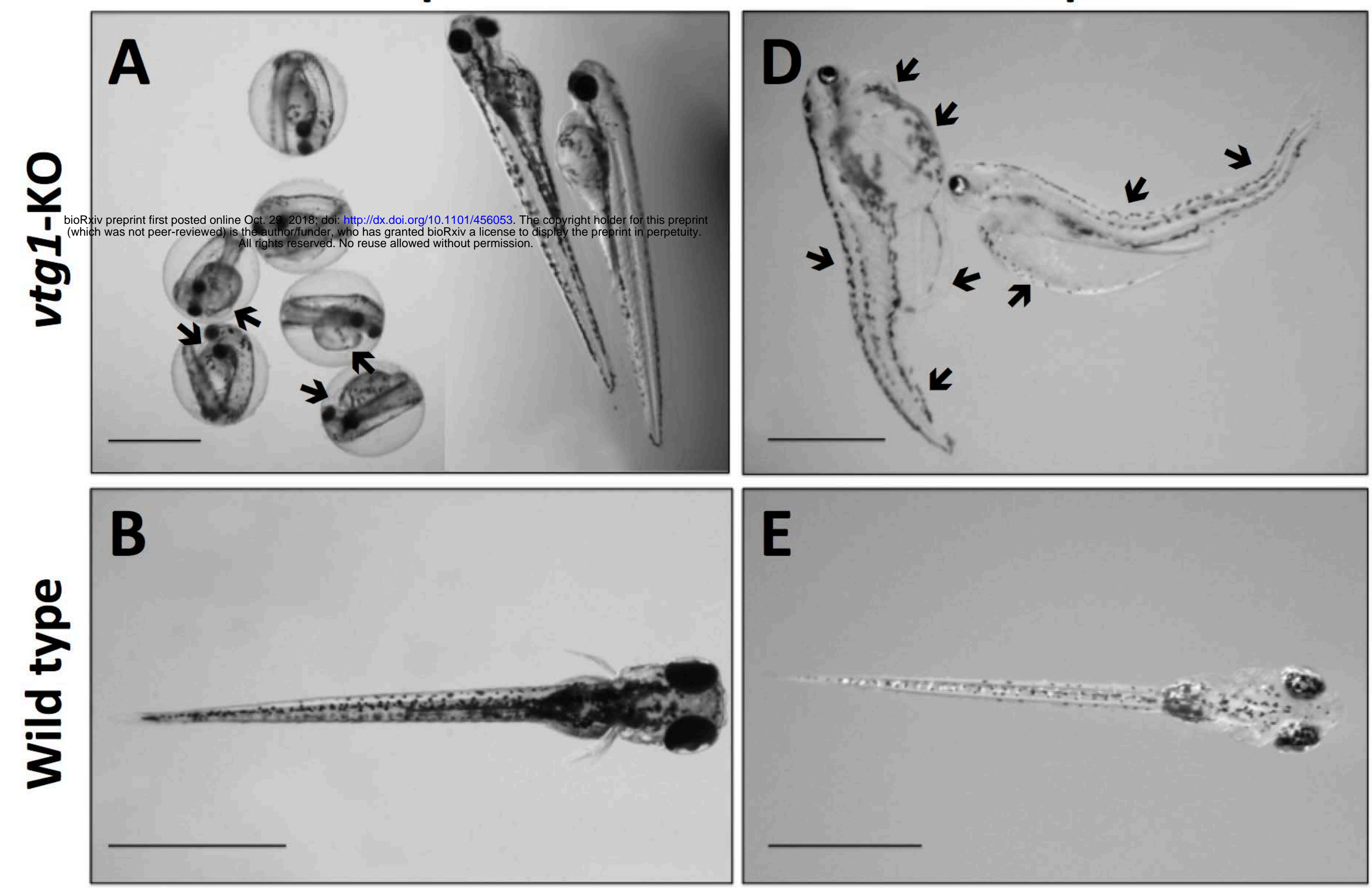

E
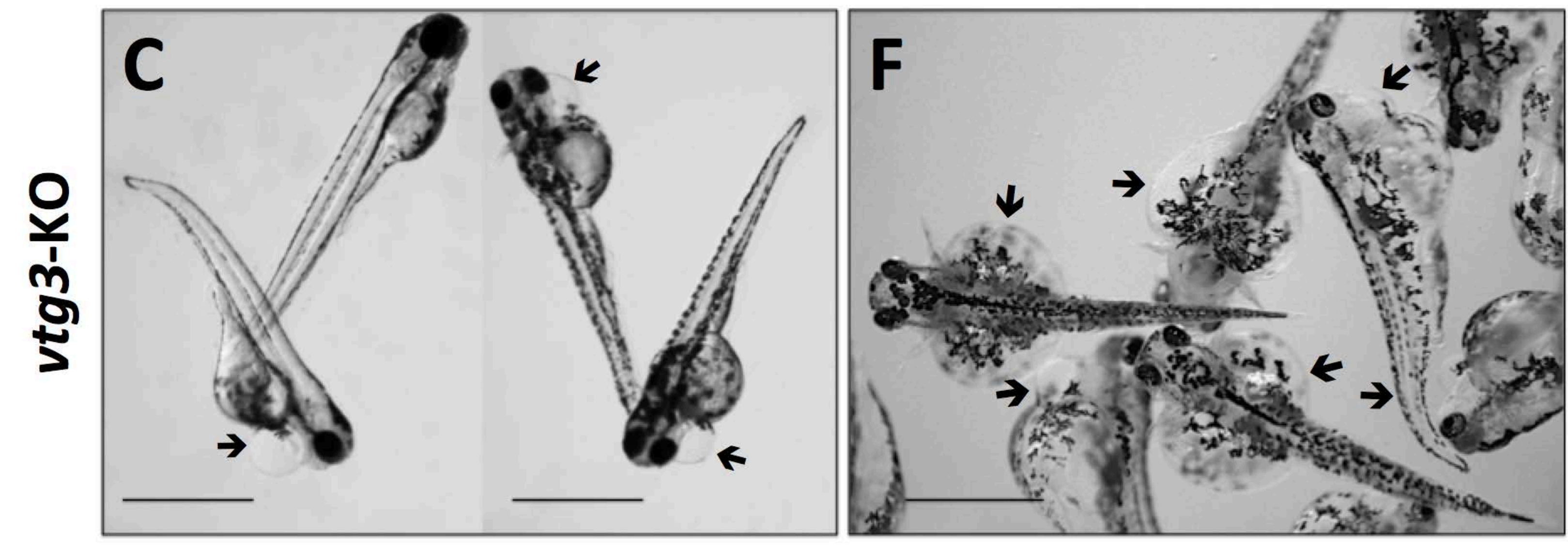


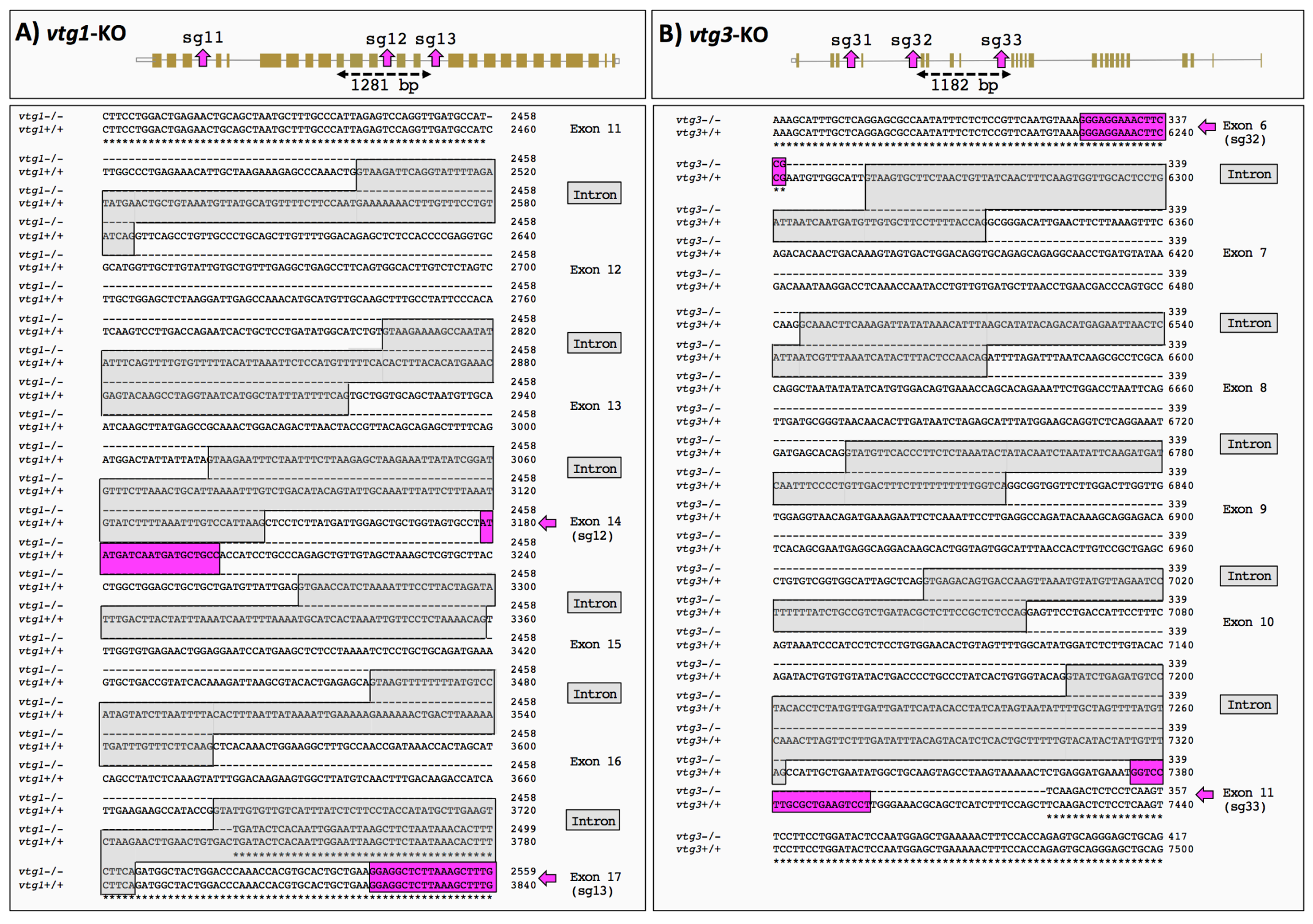


bioRxiv preprint first posted online Oct. 29, 2018; doi: http://dx.doi.org/10.1101/456053. The copyright holder for this preprint (which was not peer-reviewed) is the author/funder, who has granted bioRxiv a license to display the preprint in perpetuity. All rights reserved. No reuse allowed without permission.

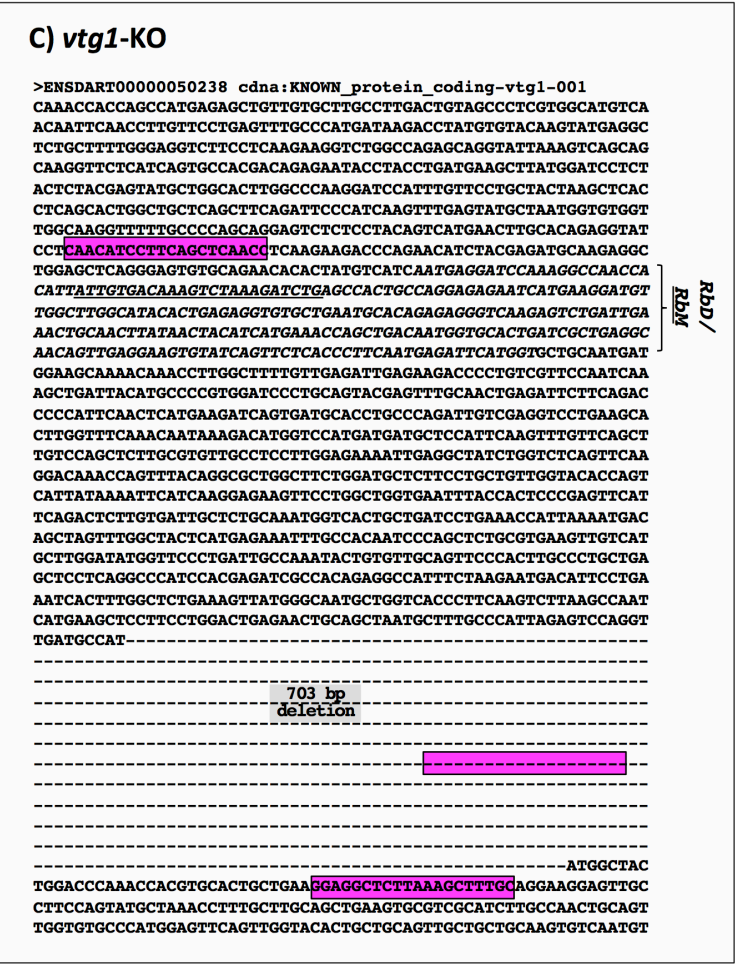

E) vtg1-KO

LvH1

Pv1 LvL1

5' QQFNLVP--- IVTKSKDL-----------------------REILDT-RMSKTAT-- 3' >ENSDART00000050238 peptide: ENSDARP00000050237 pep:KNOWN_protein_coding
MRAVVLALTVALVAC | OOFNLVPEFAHDKTYVYKYEALLLGGLPOEGLARAGIKVSSKVL MRAVVLALTVALVAC QQFNLVPETWPKDPFVATKLTTSALAAQLQIPIKFEYANGVVGKV

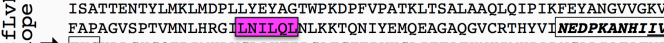
I $\Rightarrow$ TKSKDLSHCQERIMKDVGLAYTERCAECTERVKSLIETATYNYIMKPADNGALIAEATVE

†ै 0 LMKISDAPAQIVEVLKHLVSNNKDMVHDDAPFKFVQLVQLLRVASLEKIEAIWSQFKDKP

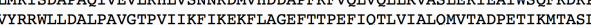
ATHEKFATIPALREVYMLGYGSLTAKYCVAVPTCPAELLRPIHEIATFATSKNDIPEITL KPLLAAEVRRILPTAVGVPMEFSWYTAAVAAASVNVQATI TPALPEKLESMTYEQLKKTD VQFQAEARP SVALQTFAVMGVNTAFIQAAVMARGKIRTIAPGKVAARADILKGNYKVEAL PVELPEHIASASFETYAVVRNIEDHSAERSVPLVPELSLQNSQASYAGDLSSEMSSVASV RAPAPFDRTLCYAVPIDIKGCVEVHSHAAFIRNSILFYIIGHHSVRAAVARAEGPAVE

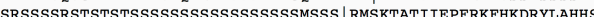

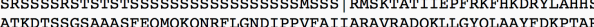
VOLIVSS IAENDNMKICADGALLSKHKVTGKFSWGAECKOYAVFAKAEAGVLGEFPARI EVEWERLPI TVTTYAKKLGKHILTAAYDTGFRFERATNSEKEIELTAALPSORSLNITAR IPEITMSKRDIYLPVAVPINPDGTFSIETYEDFLAWIQKYIKEE

\section{D) vtg3-KO}

$>$ ENSDART00000014979 cdna: KNOWN_protein_coding-vtg3-201 GGCGGCTGTGTCTCTGTCTCCTGGTAGCCCTGGCTGCCAGCGAGATGGCAAATTATGAGC CTTTTCTGAACTCGAAAAAACATACGAGTATAAATATGAAGGATTGGTACAAGTGGGAC GAGAGTCACCACACACCTTTGTCCTTCAGGTCTCAAATGTAGACTTTGAAGATTTTAATG GCATACCTGGGAAAAGTGTCTTCAGCCCFTCCAAAAACATCACTAAGCATCTGTCTGCCG CACCTGGAGTCTCAAACACAGTTGTGAATATTGTGAGGGGGATCCTTGGATTTTTACAA TCACGGTCAAAACCACACAAAGTTTTTACGAACTAATTGAGTTGGGAATTCATGGTTTGT GTCAGAGCAGTTACACTGTTGATGAAGACTCTAACGCAAAAGAGTTGATAGTAACACGAA
TTGTTGATATCACCAATGTCAACAGCCAGCATCTTTGTACAGAGGTATGGCTCTTGCAC CTGAAGACAAACTTAGCAAACAGAGAGGCGAAAGCGTTGTTTCCACTGTGAAACACACCT ACACAGTGAAGTCCACAGCAGACGGTGGTCAGATTACTAAAGCATTTGCTCAGGAGCGCC AATATTTCTCTCCGTTCAATGTAAAGGGAGGAACTTCC-------
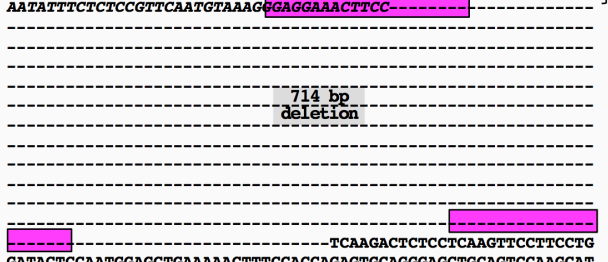
GATACTCCAATGGAGCTGAAAAACTTTCCACCAGAGTGCAGGGAGCTGCAGTCCAAGCAT TTAGGCTGCTTGCAAGCAGAGCCTCCCACAGTGTACAGGATATTGTCTTAAACCTCTTCG
TACAGAAACATTTACCAGCTGAAATCCGCATGCTGGCCTGCATAGTTCTTCTAGAGACCA

\section{F) vtg3-KO}

\section{LvH3} LvL3

$\mathbf{5}^{\prime}$ MANYEPF-- IVTRIVDIT-----------------------------------†TQDLD--- 3 >ENSDART00000014979 peptide: ENSDARP00000023158 pep:KNOWN_protein_coding RLCLCLLVALAASE | MANYEPFLNSRKTYEYKYEGLVQVGRELPHLVESALKLRCTFKII GESPHTFVLQVSNVDFEDFNGI I GKSVFSPSKNITKHLSAEISOPIIFEYSKGQITDIRT APGVSNTVVNIVRGILGFLQVTVKTTQSFYELIELGIHGLCQSSYTVDEDSNAKELIVTR IVDITNCQPASLYRGMALAPEDKLSKQRGESVVSTVKHTYTVKSTADGGQITKAFAQR QYFSPFNVKGGNFQKHLPAEIRMLACIVLLETKPSTALISVVSEVLLEEADLQVASFSYSLLKGFAKSRTPDN QHLSIACNIAMKILTRKLGHLSYRYSKNLHFDWFHDDFLFGTSADVYMLQNESPIPTKLM LKGKFHFIGRILQFLEFGIRADGLKDLFAGKIPELTKDLGISDLASILKILSNWQSLPKD KPLLTAYARVFGQEAFLMDVSRDSVQSIIKSFSPSAGKESKVWERIQDVQKGTSWHWTKP HLVYEARF IQPTCLGLPVEISKYYSVVNAVTMRAKAEINPPPKEHLGELLSSDISMQTDG FIGVTKDHFLFHGINTDLFQCGTELKSKVSMGLPWAFDLKINPKEQTYEMNLTPSKSVTE LFSVSSNVYAVLRNIEDPTSSKITPMMPETGESWQGVPLRMLPPLRDEQTRKSGMKFRQC AEAKIYGTALCIEAEAKRAHYLYPLYLIMFISAKDAKPIEKIQIQVSASR QAKPL QTYDVSMPVSA Y NPERQASVIVVASSPETFDLKVKIPERTIYKKKIPSPIELLGIEAANLTMST 
Horizontal dashed lines bearing dual arrowheads indicate regions where mutations were introduced, with the size of deletions in bp given below the arrows (1281 bp and $1182 \mathrm{bp}$ for vtg1-KO and vtg3-KO, respectively). The lower sections of panels A and $\mathbf{B}$ show Clustal Omega alignments for partial genomic sequences of the vtgl and vtg3 genes, respectively, covering regions where Cas9 introduced targeted mutations. Sequences of undisturbed wild type alleles are labeled $v \operatorname{tg} 1+/+$ and $v \operatorname{tg} 3+/+$, and sequences of homozygous mutated alleles are labeled $v \operatorname{tg} 1-/-$ and vtg3-/-, respectively. Dashes were introduced to illustrate regions where deletions occurred in the vtg1-/- and vtg3-/-sequences. Nucleotide positions are indicated by numbers on the right and asterisks indicate nucleotide identity. Target sequences are enclosed in magenta-colored boxes emphasized by magenta-colored arrows on the right. Intron sequences are given in dark gray font enclosed in light gray filled frames and are labeled by Intron on the right with the same formatting. Exons are shown in regular black font and labeled on the right with exon numbers (e.g. Exon 6, 7, 8...). Exons bearing the target sites are also labeled with the target name below in parenthesis (e.g. Exon 14/(sg12)). C-D) Location on predicted cDNA. Nucleotide sequences targeted by sgRNAs for Cas9 editing and present in the predicted transcript are framed in magenta-shaded boxes. The deleted region of the transcript is indicated by dashes replacing nucleotide residues and the size of the deletion in bp is given by gray highlighted text in this region (703 bp deletion for $v \operatorname{tg} 1$ and $714 \mathrm{bp}$ deletion for $v \operatorname{tg} 3$ ). The sequence encoding the receptor-binding domain $(\boldsymbol{R} \boldsymbol{b D})$ on the $\mathrm{LvH}$ of the respective Vtg is shown in italic bold typeface with the sequence encoding the critical, short receptor-binding motif ( $\boldsymbol{R} \boldsymbol{b} \boldsymbol{M})$ being additionally underlined. E-F) Location on predicted polypeptide sequences. Schematic representations of the yolk protein domain structures of Vtg1 (representative of zebrafish type-I Vtgs) and Vtg3 are given in $5^{\prime}>3^{\prime}$ orientation above each panel. Light gray horizontal bars represent the lipovitellin heavy and light chain $(\mathrm{LvH}, \mathrm{LvL})$ and the phosvitin $(\mathrm{Pv})$ yolk protein domains of the respective Vtg (Vtg3 lacks a Pv domain) and are labeled above in large bold type. Sequences within these bars indicate the N-terminus of each yolk protein domain, the start of which is also indicated by 
vertical bars in the polypeptide sequence shown below. The $\boldsymbol{R} \boldsymbol{b} \boldsymbol{M}$ is shown in bold italic underlined font on the gray horizontal bars in the LvH1 and LvH3 domains. The $\boldsymbol{R} \boldsymbol{b} \boldsymbol{D}$ and $\boldsymbol{R} \boldsymbol{b} \boldsymbol{M}$ are also indicated in the polypeptide sequences shown below by bold italic font with the $\boldsymbol{R} \boldsymbol{b} \boldsymbol{M}$ being additionally underlined. Residues encoded by nucleotide sequences targeted by sgRNAs for Cas9 editing are framed in magenta-shaded boxes. Cas9 created mutations (large deletions) are indicated with dashes replacing amino acid (aa) residues and the size of deletions in aa (234 aa and 239 aa for $v \operatorname{tg} 1-\mathrm{KO}$ and $v \operatorname{tg} 3-\mathrm{KO}$, respectively) in these regions are labeled by gray shaded text. Short sequences that were employed as epitopes to develop Vtg domain-specific antibodies against Vtg1-LvH (anti-zfLvH1) and Vtg3-LvL (anti-zfLvL3) are indicated by framed text on the $\mathrm{LvH}$ and $\mathrm{LvL}$ domains of $\mathrm{Vtg} 1$ and $\mathrm{Vtg} 3$, respectively, with their location also highlighted by black arrows labeled with the epitope names given by vertically-oriented text in the panel margins. 
S1 Table. Targets, primers and probes utilized in vtg1-KO and vtg3-KO studies. Target oligo an screening primer names are given according Figure 1. CRISPR recognition NGG motifs are highlighted by bold typeface on sequences. Position of primers, target sites and probes on vitellogenin (Vtg) yolk protein (YP) domains are given on the far right columns.

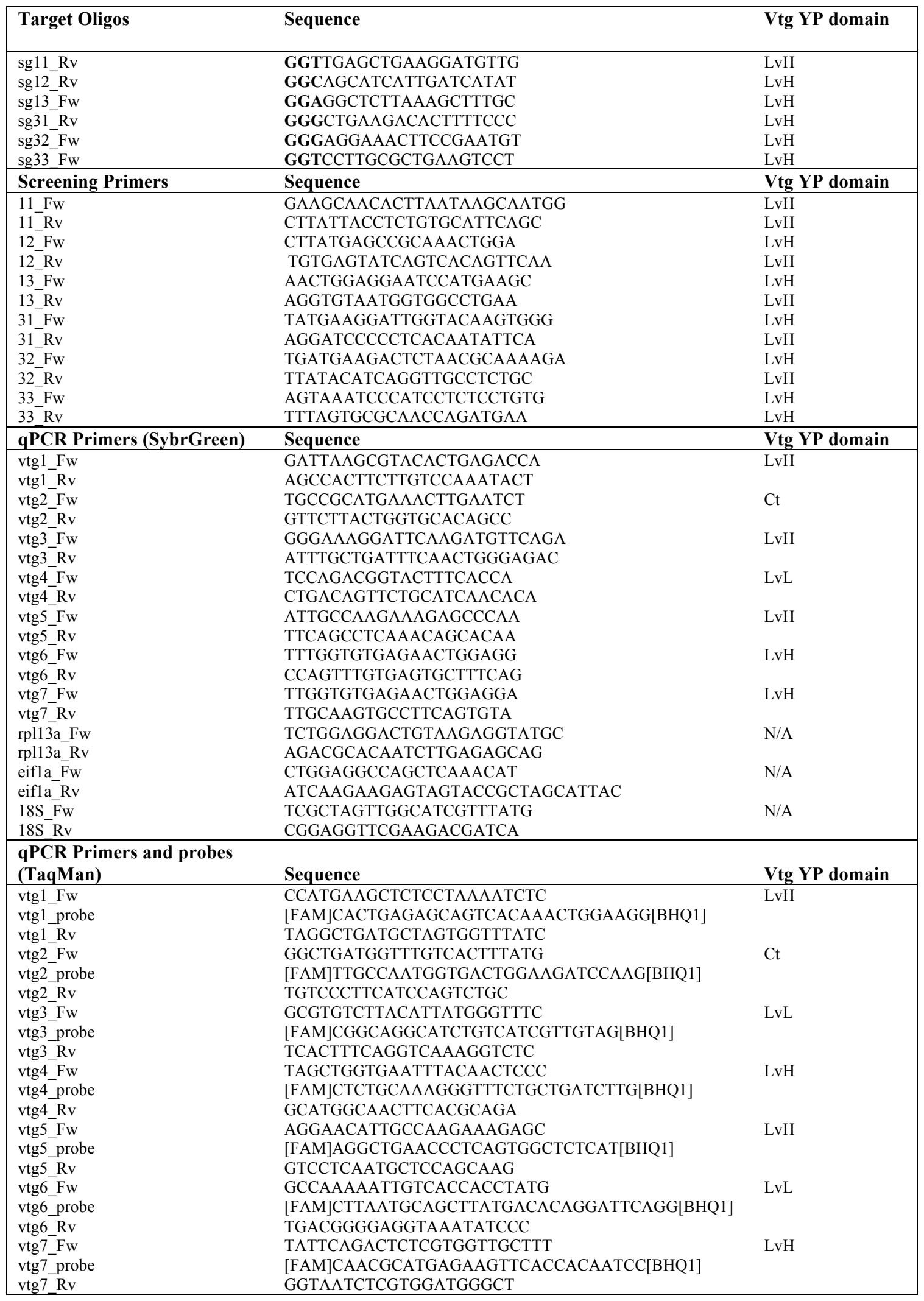

